\title{
Synthesis of $\mathrm{Sb}_{2} \mathrm{Se}_{3}$ and $\mathrm{Bi}_{2} \mathrm{Se}_{3}$ Nanoparticles in lonic Liquids at Low Temperatures and Solid State Structure of $\left[\mathrm{C}_{4} \mathrm{C}_{1} \mathrm{Im}\right]_{3}\left[\mathrm{BiCl}_{6}\right]$
}

\author{
Manuel Loor, ${ }^{[a]}$ Georg Bendt, ${ }^{[a]}$ Julian Schaumann, ${ }^{[a]}$ Ulrich Hagemann, ${ }^{[b]}$ Markus Heidelmann, ${ }^{[b]}$ \\ Christoph Wölper, ${ }^{[a]}$ Stephan Schulz ${ }^{*[a]}$
}

\begin{abstract}
Crystalline $\mathrm{Sb}_{2} \mathrm{Se}_{3}$ nanoparticles were prepared by reaction of $\mathrm{SbCl}_{3}$ with $\left(\mathrm{Et}_{3} \mathrm{Si}\right)_{2} \mathrm{Se}$ in the presence of oleylamine $(\mathrm{OA})$ in the ionic liquids $\left[\mathrm{C}_{4} \mathrm{C}_{1} \mathrm{Im}\right] \mathrm{Cl}$, whereas the reaction of $\left(\mathrm{Et}_{3} \mathrm{Si}\right)_{2} \mathrm{Se}$ with $\left[\mathrm{C}_{4} \mathrm{C}_{1} I \mathrm{~m}_{3}\left[\mathrm{BiCl}_{6}\right] 1\right.$, which was obtained from the reaction of $\mathrm{BiCl}_{3}$ with $\left[\mathrm{C}_{4} \mathrm{C}_{1} \mathrm{Im}\right] \mathrm{Cl}$ and structurally characterized by single crystal $\mathrm{X}$-ray diffraction, yielded $\mathrm{Bi}$-rich $\mathrm{Bi}_{2} \mathrm{Se}_{3}$ nanoparticles. In contrast, the reaction of the reactive IL $\left[\mathrm{C}_{4} \mathrm{C}_{1} / \mathrm{m}_{3}\left[\left.\mathrm{Bi}_{3}\right|_{12}\right]\right.$ with $\left(\mathrm{Et}_{3} \mathrm{Si}\right)_{2} \mathrm{Se}$ in the presence of oleylamine $(\mathrm{OA})$ in $\left[\mathrm{C}_{4} \mathrm{C}_{1}\right.$ Im]l gava phase-pure $\mathrm{Bi}_{2} \mathrm{Se}_{3}$ nanoparticles. The chemical composition of the nanoparticles was investigated by EDX, while possible surface contaminations were studied by XPS and IR spectroscopy. The morphology of the nanoparticles was studied by SEM and TEM.
\end{abstract}

\section{Introduction}

Antimony and bismuth chalcogenides of the general type $M_{2} E_{3}$, $(\mathrm{M}=\mathrm{Sb}, \mathrm{Bi} ; \mathrm{E}=\mathrm{Se}, \mathrm{Te})$ are promising materials for several technical applications including batteries ${ }^{[1]}$ photovoltaics and solar cells, ${ }^{[2]}$ topological insulators $(\mathrm{Tls})^{[3]}$ and thermoelectric (TE) materials. ${ }^{[4]}$ These applications often require nanostructured materials such as nanoparticles and thin films. Nanoparticles can be generally prepared either by top-down processes such as ball-milling or by bottom-up approaches, i.e. solvothermal routes, polyol processes, reduction reactions and others, which have been established in the past for the size- and shape-selective synthesis of binary and ternary antimony and bismuth chalcogenides. ${ }^{[5]}$

Bismuth selenide $\mathrm{Bi}_{2} \mathrm{Se}_{3}$ is a small band gap semiconductor with a direct band gap, $\mathrm{Eg}=0.35 \mathrm{eV},{ }^{[6]}$ while $\mathrm{Sb}_{2} \mathrm{Se}_{3}$ has an indirect energy band gap of $1.21 \mathrm{eV}$ and a direct transition at $1.22 \mathrm{eV}$ according to very recent calculations. ${ }^{[7]}$ The structure of $\mathrm{Sb}_{2} \mathrm{Se}_{3}$, which crystallizes in the space group Pnma, ${ }^{[8]}$ can be described as one-dimensional chains along the direction of the $b$-axis, which are cross-linked to give the $3 \mathrm{D}$ orthorhombic structure. $\mathrm{Bi}_{2} \mathrm{Se}_{3}$ crystallizes in the space group R-3m (tetradymite-type). ${ }^{\left[{ }^{9]}\right.}$ Both materials have received increasing interest in recent years as promising TE and $\mathrm{TI}$ materials. $\mathrm{Sb}_{2} \mathrm{Se}_{3}$ for instance shows a very high Seebeck coefficient $(1800 \mu \mathrm{V} / \mathrm{K})$, but its electrical

[a] * Prof. Dr. S. Schulz

Inorganic Chemistry and Center for Nanointegration Duisburg-Essen (CENIDE), University of Duisburg-Essen, Universitätsstr. 5-7, S07 S03 C30, D-45117 Essen

Fax: (+49) 201-183 3830, E-Mail: stephan.schulz@uni-due.de https://www.uni-due.de/ak_schulz/index_en.php

[b] Interdisciplinary Center for Analytics on the Nanoscale (ICAN), NETZ, Carl-Benz-Str. 199, 47047 Duisburg, Germany

Supporting information for this article is given via a link at the end of the document. conductivity $\left(\sigma \sim 10^{-6}-10^{-2} \Omega^{-1} \mathrm{~m}^{-1}\right)$ unfortunately is very low. ${ }^{[10]}$ However, electrical conductivity can be significantly enhanced by electrical doping for instance with $\mathrm{Ag}_{2} \mathrm{Se}^{\left[{ }^{[1]}\right.}$

$\mathrm{Sb}_{2} \mathrm{Se}_{3}$ nanoparticles with definite size and shape were typically synthesized by solvothermal processes, ${ }^{[12]}$ microwave-assisted methods, ${ }^{[13,14]}$ and hot injection method. ${ }^{[11]}$ Recently, $\mathrm{Sb}_{2} \mathrm{Se}_{3}$ nanowires with diameters ranging from 10 to $20 \mathrm{~nm}$ and length up to $30 \mu \mathrm{m}$ were prepared by reaction of triphenylantimony with dibenzyldiselenide. ${ }^{[15]} \mathrm{Bi}_{2} \mathrm{Se}_{3}$ nanoparticles were also obtained from polyol synthesis and microwave-assisted solvothermal routes, respectively. ${ }^{[16]}$

We are generally interested in the synthesis of nanostructured group 15 chalcogenide materials by gas-phase processes such as metal organic chemical vapor deposition (MOCVD) $)^{[17]}$ and atomic layer deposition (ALD) processes, ${ }^{[18]}$ which were successfully applied in our group for the deposition of thin films of binary and ternary group 15 chalcogenides. Furthermore, we developed solution-based synthetic routes and synthesized crystalline $\mathrm{Sb}_{2} \mathrm{E}_{3}\left(\mathrm{E}=\mathrm{S}\right.$, Se, Te) and $\mathrm{Bi}_{2} \mathrm{Te}_{3}$ nanoparticles by thermal decomposition of metal organic (single source) precursors in high boiling organic solvents in the presence of capping agents such as PVP or oleylamine (OA). ${ }^{[19]}$ In addition, ionic liquids (ILs) were successfully applied as novel solvent for the synthesis of $\mathrm{Sb}_{2} \mathrm{Te}_{3}$ nanoplates, which showed enhanced thermoelectric properties and high figure of merit values of up to 1.5. ${ }^{[20]}$ The use of metal organic precursors allowed the material synthesis under kinetically controlled reaction conditions at low temperatures due to the weak metal-carbon bonds. Unfortunately, their low thermal stability, which is in particular true for Bi-containing compounds, often limits their applicability in material synthesis due to the occurrences of unwanted side reactions such as thermal decomposition reactions. For instance, the synthesis of $\mathrm{Bi}_{2} \mathrm{Te}_{3}$ was often accompanied by the formation of elemental $\mathrm{Bi}$ or Bi-rich phases as side-products. We became therefore interested in the development of alternative precursors as well as alternative reaction processes.

We now report on the synthesis of phase-pure $\mathrm{Sb}_{2} \mathrm{Se}_{3}$ and $\mathrm{Bi}_{2} \mathrm{Se}_{3}$ nanoparticles by IL-based wet chemical approaches. The composition, phase purity and morphology of the materials were investigated by IR, EDX, XPS, XRD, SEM and TEM and the solid state structure of $\left[\mathrm{C}_{4} \mathrm{C}_{1} \mathrm{Im}\right]_{3}\left[\mathrm{BiCl}_{6}\right] 1$ is discussed.

\section{Results and Discussion}

We recently reported on the synthesis and solid state structure of $\left[\mathrm{C}_{4} \mathrm{C}_{1} \mid \mathrm{m}\right]_{3}\left[\left.\mathrm{Bi}_{3}\right|_{12}\right]$, which was obtained in quantitative yield by reaction of equimolar amounts of $\left[\mathrm{C}_{4} \mathrm{C}_{1} / \mathrm{m}\right] \mathrm{l}$ and $\mathrm{Bi}_{3}$, and its promising potential to serve as $\mathrm{Bi}$ source for the synthesis of 
phase-pure binary $\left(\mathrm{Bi}_{2} \mathrm{Te}_{3}\right)$ and ternary ([Bi $\left.\left.\mathrm{Sb}_{1-x}\right]_{2} \mathrm{Te}_{3}\right)$ tetradymite-type metal telluride nanoparticles in an IL-based wet chemical approach. ${ }^{[21]}$ In order to investigate the synthetic potential of this soluble and thermally stable Bi-source in more detail, we expanded our studies on the synthesis of the corresponding bismuth selenide $\mathrm{Bi}_{2} \mathrm{Se}_{3}$.

$$
\begin{aligned}
& 3\left[\mathrm{C}_{4} \mathrm{C}_{1} \mathrm{Im}\right] \mathrm{I}+3 \mathrm{Bil}_{3} \longrightarrow\left[\mathrm{C}_{4} \mathrm{C}_{1} \mathrm{Im}\right]_{3}\left[\mathrm{Bi}_{3} \mathrm{I}_{12}\right] \\
& {\left[\mathrm{C}_{4} \mathrm{C}_{1} \mathrm{Im}\right]_{3}\left[\mathrm{Bi}_{3} \mathrm{I}_{12}\right]+\left(\mathrm{Et}_{3} \mathrm{Si}\right)_{2} \mathrm{Se} \stackrel{\text { i) }}{\longrightarrow} \mathrm{Bi}_{2} \mathrm{Se}_{3}}
\end{aligned}
$$

i) $\left[\mathrm{C}_{4} \mathrm{C}_{1} \mathrm{Im}\right] \mathrm{I}, \mathrm{OA}, 150{ }^{\circ} \mathrm{C}$

Scheme 1. Synthesis of $\mathrm{Bi}_{2} \mathrm{Se}_{3}$ nanoparticles.

$\left(\mathrm{Et}_{3} \mathrm{Si}\right)_{2} \mathrm{Se}$ reacts with $\left[\mathrm{C}_{4} \mathrm{C}_{1} \mid \mathrm{m}\right]_{3}\left[\left.\mathrm{Bi}_{3}\right|_{12}\right]$ in a solution of $10 \mathrm{~mL}$ of $\left[\mathrm{C}_{4} \mathrm{C}_{1} \mathrm{Im}\right] \mathrm{I}$ in the presence of oleylamine $(\mathrm{OA})$ at $150{ }^{\circ} \mathrm{C}$ with formation of a black precipitate, which was isolated by centrifugation and purified by repeatedly washing with acetonitrile and hexane $(3 \mathrm{x})$. The reaction also proceeded at lower temperatures such as $80{ }^{\circ} \mathrm{C}$, but crystalline $\mathrm{Bi}_{2} \mathrm{Se}_{3}$ were only obtained at higher temperature. The soluble reaction products were further investigated by ${ }^{29} \mathrm{Si}$ NMR spectroscopy to identify the reaction mechanism (Fig. 1).

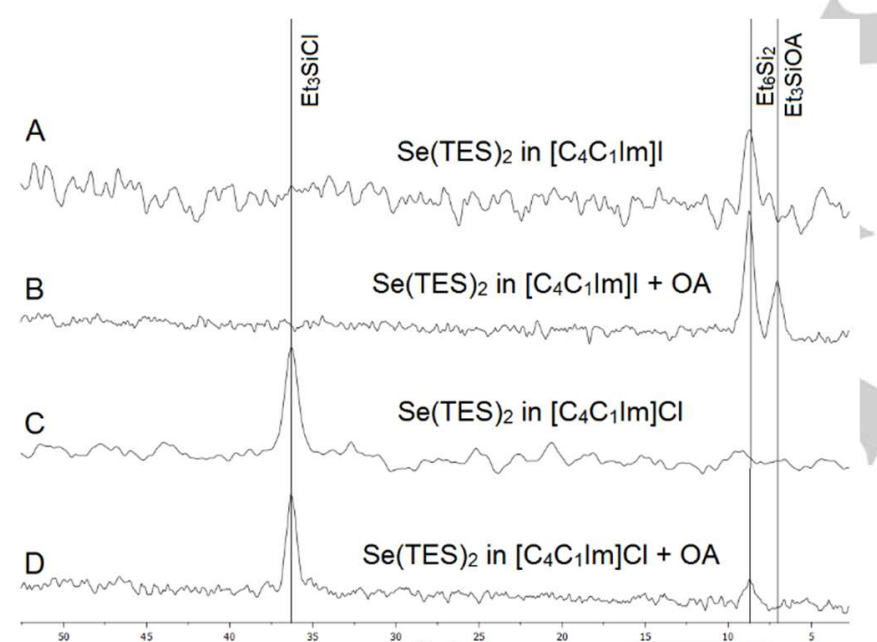

Figure 1. ${ }^{29} \mathrm{Si} \mathrm{NMR}$ spectra of the products of the reaction of $\left(\mathrm{Et}_{3} \mathrm{Si}\right)_{2} \mathrm{Se}$ with $\left[\mathrm{C}_{4} \mathrm{C}_{1} \mid \mathrm{m}_{3}\right]_{3}\left[\left.\mathrm{Bi} \mathrm{i}_{3}\right|_{2}\right](\mathrm{A}, \mathrm{B})$ and $\mathrm{BiCl}_{3}(\mathrm{C}, \mathrm{D})$ at $150{ }^{\circ} \mathrm{C}$.

$\left(\mathrm{Et}_{3} \mathrm{Si}\right)_{2} \mathrm{Te}$ reacted with $\left[\mathrm{C}_{4} \mathrm{C}_{1} \mathrm{Im}\right]_{3}\left[\mathrm{Bi}_{3} \mathrm{l}_{12}\right]$ in $\left[\mathrm{C}_{4} \mathrm{C}_{1} \mathrm{Im}\right] \mathrm{l}$ with formation of $\mathrm{Et}_{3} \mathrm{Sil}$ (dehalosilylation reaction) and $\mathrm{Si}_{2} \mathrm{Et}_{6}$ (1:3 molar ratio), which was formed by homolytic cleavage of the Te$\mathrm{Si}$ bond, ${ }^{[21]}$ while the reaction proceeded with elimination of silylamine $\left(\mathrm{Et}_{3} \mathrm{SiOA}\right)$ and $\mathrm{Si}_{2} \mathrm{Et}_{6}(2: 1$ molar ratio) in the presence of OA. ${ }^{[22] ~ I n ~ c o n t r a s t, ~ t h e ~ r e a c t i o n ~ o f ~}\left(\mathrm{Et}_{3} \mathrm{Si}\right)_{2} \mathrm{Se}$ with $\left[\mathrm{C}_{4} \mathrm{C}_{1} \mid \mathrm{m}\right]_{3}\left[\mathrm{Bi}_{3} \mathrm{I}_{12}\right]$ in the absence of $\mathrm{OA}$ exclusively yielded $\mathrm{Si}_{2} \mathrm{Et}_{6}$, while $\mathrm{Et}_{3} \mathrm{SiOA}$ and $\mathrm{Si}_{2} \mathrm{Et}_{6}$ (2:1 molar ratio) were formed in the presence of OA was shown by ${ }^{29} \mathrm{Si}$ NMR spectroscopy (Fig. 1A, B). The formation of $\mathrm{Et}_{3} \mathrm{Sil}$ was not detected at all. These findings prove that $\mathrm{OA}$ is more reactive toward $\left(\mathrm{Et}_{3} \mathrm{Si}\right)_{2} \mathrm{Se}$ compared to the iodide anion, while in the absence of OA, the homolytic Se-Si bond breakage reaction is preferred.

The elemental composition of the resulting material as determined by EDX proved the formation of stoichiometric bismuth selenide $\mathrm{Bi}_{2} \mathrm{Se}_{3}$ (table 1). According to IR spectroscopy studies, the material does not contain significant amounts of organic molecules as was shown by comparing the IR spectrum of the nanoparticles with those of pure OA, $\left[\mathrm{C}_{4} \mathrm{C}_{1} \mathrm{Im}\right] \mathrm{I}$ and acetonitrile (Fig. 2).

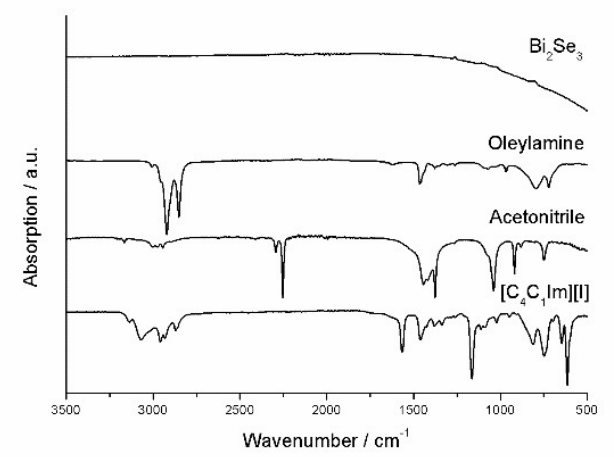

Figure 2. IR spectra of $\mathrm{Bi}_{2} \mathrm{Se}_{3}$ nanoparticles synthesized by reaction of $\left(\mathrm{Et}{ }_{3} \mathrm{Si}\right)_{2} \mathrm{Se}$ with $\left[\mathrm{C}_{4} \mathrm{C}_{1} \mathrm{Im}\right]_{3}\left[\mathrm{Bi}_{3} \mathrm{I}_{12}\right]$ in $\left[\mathrm{C}_{4} \mathrm{C}_{1} \mathrm{Im}\right] \mathrm{l}$ in the presence of $\mathrm{OA}$ at $150{ }^{\circ} \mathrm{C}$.

In contrast, XPS studies (Fig. 3) proof the existence of carbon as well as a minimal amount of iodine, which most likely results from a residual IL layer on the surface of the nanoparticles. This thin surface layer can't be detected by IR spectroscopy but by XPS due to the higher surface sensitivity. The binding energy of the main lines in the $\mathrm{Bi}$ and Se signals agree well with literature data of $\mathrm{Bi}_{2} \mathrm{Se}_{3}$ surfaces. ${ }^{[23]}$ Selenium oxides (binding energy comparable to $\mathrm{SeO}_{2}$ ) were hardly visible (see inlet Fig. 3), while roughly $5 \%$ of the $\mathrm{Bi}$ surface atoms are either present as bismuth oxides, most likely mixed bismuth oxoselenides $\left(\mathrm{Bi}_{2}\left(\mathrm{O}_{\mathrm{x}} \mathrm{Se}_{1-\mathrm{x}}\right)_{3}, 90 \%\right)$, or iodides $\left(\mathrm{Bil}_{3}\right.$ or $\left.\mathrm{BiOl}, 10 \%\right)$. The presence of bismuth oxides or iodides in these low quantities result in a shoulder to the large metal $\mathrm{Bi}$ signal and are not distinguishable.
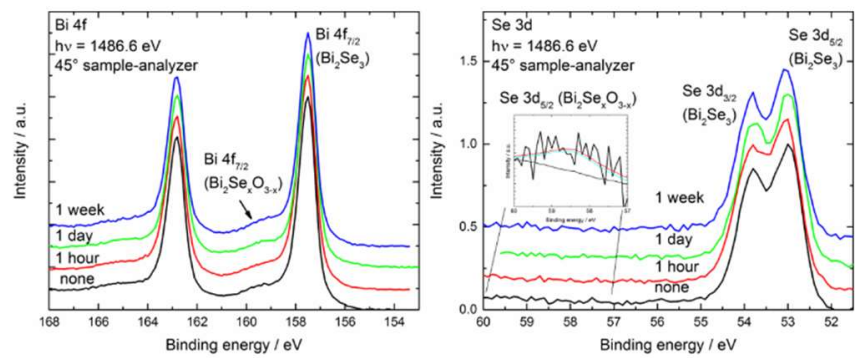

Figure 3. XPS $\mathrm{Bi} 4 \mathrm{f}$ and $\mathrm{Se} 3 \mathrm{~d}$ signals of $\mathrm{Bi}_{2} \mathrm{Se}_{3}$ nanoparticles synthesized by reaction of $\left(\mathrm{Et}_{3} \mathrm{Si}\right)_{2} \mathrm{Se}$ with $\left[\mathrm{C}_{4} \mathrm{C}_{1} / \mathrm{m}_{3}\left[\left.\mathrm{Bi}_{3}\right|_{12}\right]\right.$ in $\left[\mathrm{C}_{4} \mathrm{C}_{1} / \mathrm{m}\right] \mathrm{l}$ in the presence of OA at $150{ }^{\circ} \mathrm{C}$. No change in the metal oxide content is visible upon exposure to air. 
The amount of bismuth and selenium oxides did not increase upon exposure to air. A very recent XPS study clearly revealed that $\mathrm{Bi}_{2} \mathrm{Te}_{3}$ and $\mathrm{Bi}_{2} \mathrm{Te}_{2}$ Se easily form the corresponding oxides upon expose to air, while $\mathrm{Bi}_{2} \mathrm{Se}_{3}$ was significantly more stable. ${ }^{[2]}$ Comparable findings were previously reported ${ }^{[25]}$ and also observed for $\mathrm{Bi}_{2} \mathrm{Te}_{3}$ nanoparticles, which were shown to form bismuth oxides and tellurium oxides within a day upon expose toward air. ${ }^{[21]}$

The material was also investigated by powder X-ray diffraction (PXRD), which clearly proved the formation of crystalline $\mathrm{Bi}_{2} \mathrm{Se}_{3}$ nanoparticles (Fig. 4).

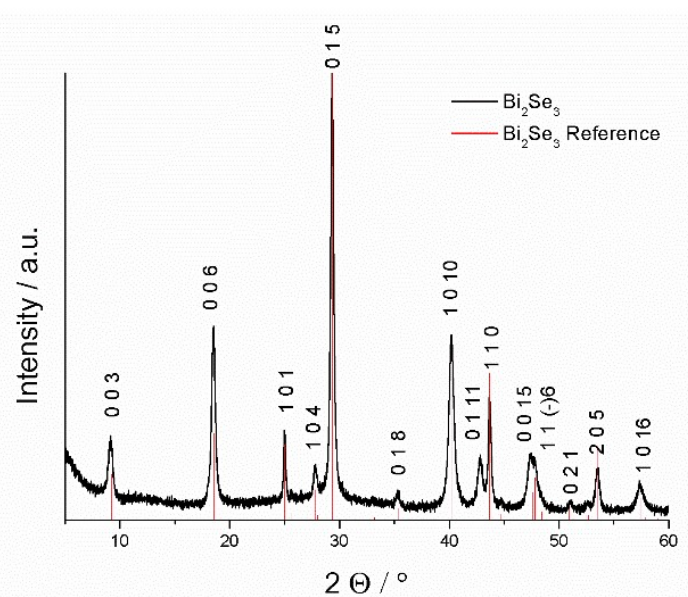

Figure 4. PXRD of $\mathrm{Bi}_{2} \mathrm{Se}_{3}$ nanoparticles synthesized by reaction of $\left(\mathrm{Et}_{3} \mathrm{Si}\right)_{2} \mathrm{Se}$ with $\left[\mathrm{C}_{4} \mathrm{C}_{1} / \mathrm{m}_{3}\left[\mathrm{Bi}_{3} \mathrm{l}_{12}\right]\right.$ in $\left[\mathrm{C}_{4} \mathrm{C}_{1} \mathrm{~m}\right] \mathrm{l}$ in the presence of $\mathrm{OA}$ at $150{ }^{\circ} \mathrm{C}$ and reference for $\mathrm{Bi}_{2} \mathrm{Se}_{3}$ (PDF 901-1965). ${ }^{[26]}$

The peaks can be indexed on the basis of phase-pure $\mathrm{Bi}_{2} \mathrm{Se}_{3}$ (PDF 901-1965). The lattice parameters were refined to $a=$ 4.144(9) $\AA, c=28.686(5) \AA$ and $V=426.8(3) \AA^{3}$, and are in good agreement with values reported for $\mathrm{Bi}_{2} \mathrm{Se}_{3}$ (PDF 901-1965). The $X R D$ pattern shows a strong texture effect, since the hexagon arrange with the c-axis perpendicular to the sample holder as was also observed in REM photographs (Fig. 5). As a consequence, the intensity of the (00I) reflections is strongly enhanced as can be seen in particular for the (006) reflection, whereas the intensity of the $(015)$ reflection is discriminated compared to the standard card. In addition, the XRD pattern shows anisotropic peak broadening since the $\mathrm{Bi}_{2} \mathrm{Se}_{3}$ platelets are relatively large $(\sim 300 \mathrm{~nm})$ but also very thin. For this reason, the XRD pattern shows strong peak broadening with exception of the (110) reflection at $43.8^{\circ}$.

The morphology of the $\mathrm{Bi}_{2} \mathrm{Se}_{3}$ nanoparticles was investigated by SEM and TEM. According to the SEM studies, the material contains largely agglomerated hexagonal $\mathrm{Bi}_{2} \mathrm{Se}_{3}$ nanoplates, whose size ranges from 50 to $500 \mathrm{~nm}$ (Fig. 5). The agglomeration, which also indicates an almost capping-layer free surface, has been previously observed for $\mathrm{Sb}_{2} \mathrm{Te}_{3}$ and $\mathrm{Bi}_{2} \mathrm{Te}_{3}$ as well as $\left(\mathrm{Sb}_{\mathrm{x}} \mathrm{Bi}_{1-\mathrm{x}}\right)_{2} \mathrm{Te}_{3}$ nanoparticles as-synthesized in ILs. ${ }^{[20,21]}$ The shape and size of the hexagonal $\mathrm{Bi}_{2} \mathrm{Se}_{3}$ nanoplates is similar to those synthesized by other wet chemical bottom up methods, which typically use shape and size controlling agents, and clearly results from the tetradymite-type layer structure. However, compared to standard capping agents such as oleylamine or PVP, the IL used herein obviously binds weaker to the surface and can therefore be easily washed away, resulting in the formation of largely agglomerated nanoparticles. ${ }^{[27]}$
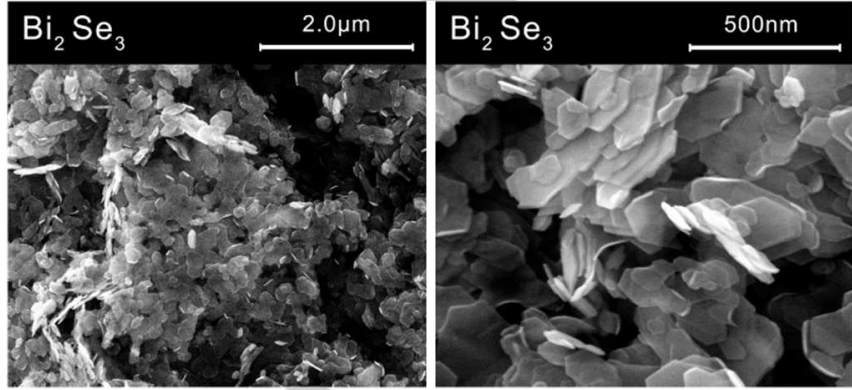

Figure 5. SEM image of $\mathrm{Bi}_{2} \mathrm{Se}_{3}$ nanoparticles synthesized by reaction of $\left(\mathrm{Et}_{3} \mathrm{Si}\right)_{2} \mathrm{Se}$ with $\left[\mathrm{C}_{4} \mathrm{C}_{1} / \mathrm{m}\right]_{3}\left[\mathrm{Bi}_{3} \mathrm{l}_{12}\right]$ in $\left[\mathrm{C}_{4} \mathrm{C}_{1} \mathrm{~lm}\right] \mathrm{l}$ in the presence of $\mathrm{OA}$ at $150{ }^{\circ} \mathrm{C}$.

TEM bright field images show the formation of hexagonal plates between 50 to $200 \mathrm{~nm}$ in size. A high-resolution high-angle annular dark-field (HAADF) image of the $\mathrm{Bi}_{2} \mathrm{Se}_{3}$ structure projected along the [5 1010 ] direction is given in Fig. 6 (right), clearly proving the crystalline nature of the material. The measured closest distance between two atomic columns is 0.29 $\mathrm{nm}$, which is in good agreement to the value of $0.287 \mathrm{~nm}$ reported in the literature. ${ }^{[28]}$

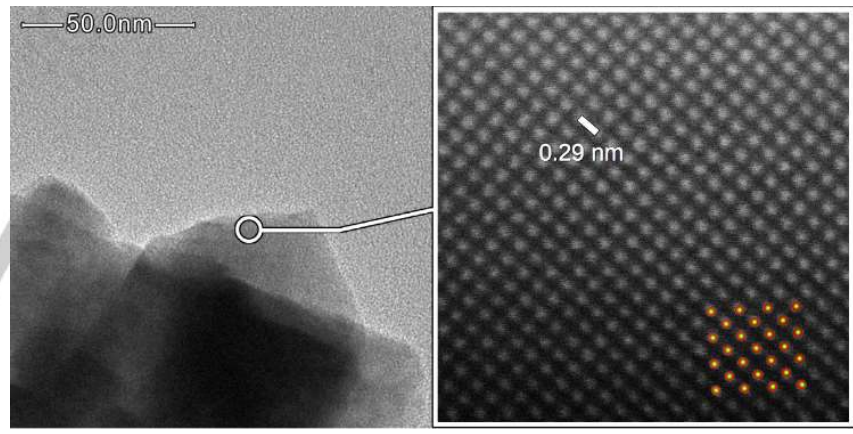

Figure 6. Conventional bright field TEM (left) and HAADF STEM (right) images of $\mathrm{Bi}_{2} \mathrm{Se}_{3}$ nanoparticles projected along [5 10 1] direction. Model structure of $\mathrm{Bi}_{2} \mathrm{Se}_{3}$ as overlay (orange: $\mathrm{Bi}$, yellow: $\mathrm{Se}$ ).

The use of the reactive IL $\left[\mathrm{C}_{4} \mathrm{C}_{1} I \mathrm{~m}\right]_{3}\left[\mathrm{Bil}_{12}\right]$, which is easily obtained from the reaction of $\mathrm{Bil}_{3}$ with an equimolar amount of $\left[\mathrm{C}_{4} \mathrm{C}_{1} \mathrm{Im}\right] \mathrm{l}$, in material synthesis avoids the formation of elemental bismuth or of bismuth-rich material phases, i.e. BiTe or $\mathrm{Bi}_{4} \mathrm{Te}_{3}$ in case of bismuth tellurides, as is often observed in the synthesis of bismuth chalcogenides. This finding most likely results from its high reactivity but increased thermal stability compared to many (organometallic) bismuth sources. The reactions of $\mathrm{Se}\left(\mathrm{SiEt}_{3}\right)_{2}$ with $\left[\mathrm{C}_{4} \mathrm{C}_{1} / \mathrm{m}\right]_{3}\left[\mathrm{Bil}_{12}\right]$ were found to proceed at temperatures as low as $80{ }^{\circ} \mathrm{C}$, which is higher compared to those with $\mathrm{Te}\left(\mathrm{SiEt}_{3}\right)_{2}$, which already occurred at ambient temperature, but below typical reaction temperatures as applied in polyol processes (up to $250{ }^{\circ} \mathrm{C}$ ) and in reduction 
reactions or thermal decomposition reactions. ${ }^{[29]}$ The higher reaction temperature in case of the reaction with $\mathrm{Se}\left(\mathrm{SiEt}_{3}\right)_{2}$ agrees with the decreasing $E-S i$ bond energy $(E=S e, T e)$ with increasing atomic number. However, in order to obtain highly crystalline material phases in a reasonable amount of time, reaction temperatures of $100(\mathrm{Te})$ and $150{ }^{\circ} \mathrm{C}(\mathrm{Se})$ as well as prolonged reaction times of at least 2-3 $\mathrm{h}$ are necessary. Unfortunately, the homolytic E-Si bond breakage becomes more likely under these reaction conditions, which results in the formation of hexaethyldisilane $\mathrm{Si}_{2} \mathrm{Et}_{6}$. However, its formation can be fully avoided $(E=T e)$ or suppressed $(E=S e)$ if the reactions are performed in the presence of oleylamine $(O A)$, which initially reacts with $\mathrm{E}\left(\mathrm{SiEt}_{3}\right)_{2}$ with formation of the silylamine $\left(\mathrm{Et}_{3} \mathrm{SiOA}\right)$ and chalcogenide polyanions, which then smoothly react with $\left[\mathrm{C}_{4} \mathrm{C}_{1} \mathrm{Im}\right]_{3}\left[\left.\mathrm{Bi}_{3}\right|_{12}\right]$ with formation of phase-pure $\mathrm{Bi}_{2} \mathrm{E}_{3}$.

To further expand the capability of halogenidobismuthates to serve as starting reagents in material synthesis, we investigated the reaction of $\mathrm{BiCl}_{3}$ and $\left[\mathrm{C}_{4} \mathrm{C}_{1} \mathrm{Im}\right] \mathrm{Cl}$. The reaction with $\mathrm{a}$ threefold amount of $\left[\mathrm{C}_{4} \mathrm{C}_{1} \mathrm{Im}\right] \mathrm{Cl}$ yielded a liquid compound, from which a single crystal of $\left[\mathrm{C}_{4} \mathrm{C}_{1} \mathrm{Im}\right]_{3}\left[\mathrm{BiCl}_{6}\right] 1$ was obtained by recrystallization from a solution in ethanol. 1 crystallizes in the orthorhombic space group Pna2 1 with two formula units in the asymmetric unit (Fig. 7).
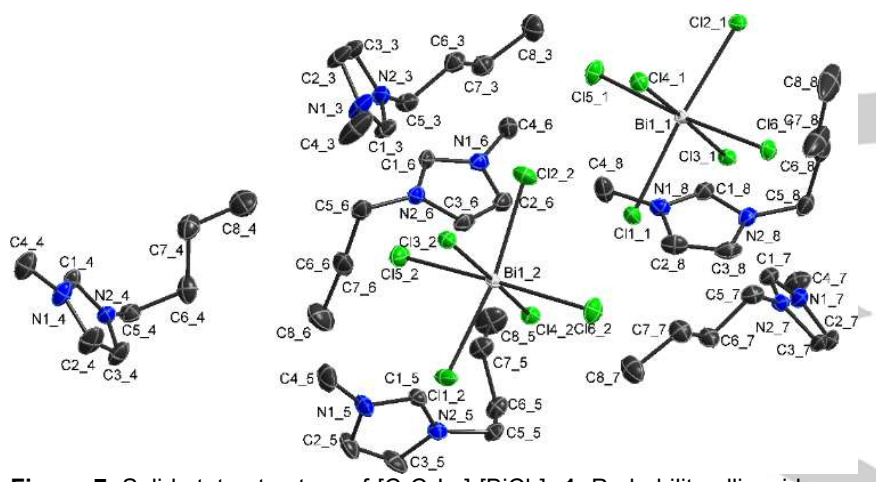

Figure 7. Solid state structure of $\left[\mathrm{C}_{4} \mathrm{C}_{1} \mid \mathrm{m}\right]_{6}\left[\mathrm{BiCl}_{6}\right]_{2}$ 1. Probability ellipsoids are displayed at $50 \%$ probability levels and hydrogen atoms are omitted for clarity. Selected bond lengths $[\AA]$ and angles [ $\left.{ }^{\circ}\right]: \mathrm{Bi} 1 \_1-\mathrm{Cl} 6$ _1 2.6790(12), Bi1_1-Cl4_1 2.6906(11), Bi1_1-Cl2_1 2.7080(10), Bi1_1-Cl3_1 2.7191(10), Bi1_1-Cl1_1 2.7239(10), Bi1_1-Cl5_1 2.7404(11), Bi1_2-Cl4_2 2.6829(10), Bi1_2-Cl5_2 2.6845(13), $\mathrm{Bi}^{-} 2-\mathrm{Cl}_{1}{ }_{2} 2$ 2.6913(10), $\mathrm{Bi}^{-} 2-\mathrm{Cl}_{2} 2$ 2.7155(10), $\mathrm{Bi}^{-} 2-\mathrm{Cl}_{3}{ }_{2}$ 2.7398(10), Bi1_2-Cl6_2 2.7643(12); Cl6_1-Bi1_1-Cl4_1 86.72(4), Cl6_1$\mathrm{Bi} 1$ 1-Cl2_1 85.87(4), Cl4_1-Bi1_1-Cl2_1 92.97(3), Cl6_1-Bi1_1-Cl3_1 89.9̄7(4), Cl4_1-Bi1_1-Cl3_1 175.97(4), Cl2_1-Bi1_1-Cl3_1 89.08(3), Cl6_1$\mathrm{Bi} 1$ 1-Cl1_1 90.23(3), $\mathrm{Cl} 4$ 1-Bi1 1-Cl1 1 89.37(3), Cl2 1-Bi1 1-Cl1 1 175.32(4), Cl3 1-Bi1 1-Cl1 1 88.35(3), Cla $1-\mathrm{Bi} 1$ 1-Cl5 $1174.53(3)$, Cl4 $1-$ Bi1_1-Cl5_1 90.40(4), Cl2_1-Bi1_1-Cl5_1 89.64(3), Cl3_1-Bi1_1-Cl5_1 93.09(4), Cl1_1-Bi1_1-Cl5_194.40(4), Cl4_2-Bi1_2-Cl5_2 87.24(4), Cl4_2$\mathrm{Bi} 12-\mathrm{Cl} 12-92.97(3), \quad \overline{\mathrm{Cl}} 5$ 2-Bi1 2-Cl1 2 85.75(4), $\mathrm{Cl} 4$ 2-Bi1 2-Cl 22

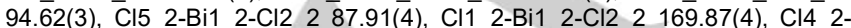
$\mathrm{Bi} 1$ 2-Cl3_2 173.96(4), $\mathrm{Cl} 5$ 2-Bi1_2-Cl3_2 86.97(4), Cl1_2-Bi1_2-Cl3_2 88.33(3), Cl2_2-Bi1_2-Cl3_2 83.44(3), Cl4_2-Bi1_2-Cl6_2 88.15(4), Cl5_2

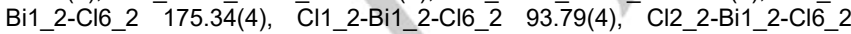
93.16(4), Cl3_2-Bi1_2-Cl6_2 97.65(4).

The $\mathrm{BiCl}_{6}{ }^{3-}$ ions can be described as slightly distorted octahedra. Perpendicular to the a-axis, the anions form layers of interconnected six-membered rings similar to those observed in the wurzite structure, however, the lower symmetry prevents a wurzite-type connection of the layers
A closer inspection reveals that the opposing $\mathrm{Bi}-\mathrm{Cl}$ bond lengths slightly differ (Bi1_1: mean $2.693 \AA$ and $2.729 \AA$ with differences ranging from 1.6 to $6.1 \mathrm{pm}$; Bi1_2: mean $2.686 \AA$ and $2.740 \AA$ with differences ranging from 2.4 to $8.0 \mathrm{pm}$ ) and that the differing $\mathrm{Bi}-\mathrm{Cl}$ bond lengths are grouped in a fac-arrangement. The cisoid $\mathrm{Cl}-\mathrm{Bi}-\mathrm{Cl}$ bond angles range from $85.87(4)$ to $94.40(4)^{\circ}$ (Bi1_1) and 83.44(3) to $97.65(4)^{\circ}$ (Bi1_2), and the transannular $\mathrm{Cl}-\mathrm{Bi}-\mathrm{Cl}$ bond angles deviate from linearity (Bi1_1: 174.53(3) 175.97(4) ${ }^{\circ}$; Bi1_2: 169.87(4) - 175.34(4) ${ }^{\circ}$ ). The deviation from linearity in the hexachlorobismuthate ion is comparable to that observed in other hexachlorobismuthates. ${ }^{[30]}$ A statistical analysis of the CSD (mean difference of $10.5 \mathrm{pm}$ with a std. deviation of $10 \mathrm{pm}$ ) shows absolute bond lengths ranging from $2.6790(12)$ to $2.7643(12) \AA$ (CSD mean 2.71(6) $\AA$ ), while the bond angles show the expected values for a slightly distorted octahedron (mean $90.00^{\circ}$ and $174.17^{\circ}$ ). ${ }^{[31]}$ However, considering the standard uncertainties of the $\mathrm{Bi}-\mathrm{Cl}$ bond lengths and the standard deviation of the CSD results, these findings, which match theoretical expectations, should not be overrated.

The hexachlorobismuthate(III) anion, a $14 \mathrm{e}$ system in which the electron lone pair formally shows a high (formally stereochemically inactive) s-character, often shows high variations $(\sigma)$ in the $\mathrm{Bi}-\mathrm{Cl}$ bond lengths and $\mathrm{Cl}-\mathrm{Bi}-\mathrm{Cl}$ angles. The distortion of the octahedral coordination of the $\left[\mathrm{BiCl}_{6}\right]^{3-}$ anion has been traditionally explained as accommodating the spatial requirements of the electron lone pair, which points away from the shortest $\mathrm{Bi}-\mathrm{Cl}$ bonds in the octahedron, while more recent studies addressed the distortion to the softness of this specific anion. ${ }^{[32]}$ In addition, the variations can be significantly enhanced in case of the presence of intermolecular (weak) hydrogen bonding. ${ }^{[30 c]}$ Orgel attributed the structural distortion by mixing of the $s$ and $p$-orbital of the cation, ${ }^{[33 a]}$ which was confirmed by Wheeler and Kumar using extended Hückel calculations, according to which the trigonal distortion in the molecular anion $\left[\mathrm{BiCl}_{6}\right]^{3-}$ results from the mixing of the cationic s orbital (HOMO) and the cationic pz orbital (LUMO). ${ }^{[33 b]}$ This description implies that the lone pair electrons in $\left[\mathrm{BiCl}_{6}\right]^{3-}$ on the central atom are hybridized toward the longer bonds and larger angles. In agreement with this description, the shorter $\mathrm{Bi}-\mathrm{Cl}$ bonds $\mathrm{Bi1} 1$ 1$\mathrm{Cl} / 4 / 6$ and $\mathrm{Bi} 1 \_2-\mathrm{Cl} 1 / 4 / 5$ in 1 correspond to the smaller $\mathrm{Cl}-\mathrm{Bi}-\mathrm{Cl}$ angles, while the longer $\mathrm{Bi}-\mathrm{Cl}$ bonds define the larger $\mathrm{Cl}-\mathrm{Bi}-\mathrm{Cl}$ angle. Alternatively, the bonding situation in the hexachlorobismuthate(III) anion can be formally described as asymmetrical $4 \mathrm{e} 3 \mathrm{c}$ bond or as $\mathrm{BiCl}_{3}$ with three additionally coordinated chloride anions.

Unfortunately, the reaction of $\left(\mathrm{Et}_{3} \mathrm{Si}\right)_{2} \mathrm{Se}$ with $\mathrm{BiCl}_{3}$ in a solution of $\left[\mathrm{C}_{4} \mathrm{C}_{1} \mathrm{Im}\right] \mathrm{Cl}$ in the presence of oleylamine did not yield phasepure $\mathrm{Bi}_{2} \mathrm{Se}_{3}$. The reaction proceeded with elimination of $\mathrm{Et}_{3} \mathrm{SiCl}$ (dehalosilylation) and formation of $\mathrm{Si}_{2} \mathrm{Et}_{6}$ (2:1 molar ratio) as shown in Fig. 1D. Obviously, the chloride anion is far more reactive than the iodide anion, resulting in dehalosilylation (Fig. $1 \mathrm{C})$, while the less reactive iodide results in homolytic bond cleavage and formation of $\mathrm{Si}_{2} \mathrm{Et}_{6}$ (Fig. 1A). Even though the XRD shows the formation of crystalline $\mathrm{Bi}_{2} \mathrm{Se}_{3}$ material in both cases, the resulting materials were Bi-rich according to EDX analysis (Bi 50\%, Se 50\%). 
Since $\left[\mathrm{C}_{4} \mathrm{C}_{1} \mathrm{Im}\right]_{3}\left[\mathrm{Bi}_{3} \mathrm{l}_{12}\right]$ was successfully applied for the synthesis of $\mathrm{Bi}_{2} \mathrm{Se}_{3}$ and $\mathrm{Bi}_{2} \mathrm{Te}_{3}$ nanoparticles, ${ }^{[21]}$ we became interested to expand this procedure to the synthesis of the comparable antimony chalcogenides and turned our attention to the synthesis of antimony-containing reactive ILs. Halogenidoantimonates such as the $\left[\mathrm{Sb}_{3} \mathrm{X}_{11}\right]^{2-}$ dianions $(\mathrm{X}=\mathrm{Br}$, I) are well known and were found for instance in $\left[\mathrm{Cu}(\mathrm{MeCN})_{4}\right]_{2}\left[\mathrm{Sb}_{3} \mathrm{X}_{11}\right] \cdot{ }^{[34]}$ We therefore investigated the reaction of $\mathrm{Sbl}_{3}$ with $\left[\mathrm{C}_{4} \mathrm{C}_{1} \mathrm{Im}\right] \mathrm{l}$, but we were not able to crystallize a specific halogenidoantimonate. The same was true for the reaction of $\mathrm{SbCl}_{3}$ with $\left[\mathrm{C}_{4} \mathrm{C}_{1} \mathrm{Im}\right] \mathrm{Cl}$. We therefore turned our attention to the reaction of a mixture of $\mathrm{Sbl}_{3},\left[\mathrm{C}_{4} \mathrm{C}_{1} \mathrm{Im}\right] \mathrm{I}$ and $\mathrm{OA}$ with $\left(\mathrm{Et}_{3} \mathrm{Si}\right)_{2} \mathrm{Se}$, but this reaction only yielded a Sb-rich material phase according to EDX analysis (Sb $59 \%$ Se $39 \%$, I 2 \%) rather than the expected $\mathrm{Sb}_{2} \mathrm{Se}_{3}$. Even prolonged reaction times $(24 \mathrm{~h})$ and high reaction temperatures $\left(200^{\circ} \mathrm{C}\right)$ did not yield stoichiometric $\mathrm{Sb}_{2} \mathrm{Se}_{3}$. In remarkable contrast, the analogous reaction of $\left(\mathrm{Et}_{3} \mathrm{Si}\right)_{2} \mathrm{Se}$ with $\mathrm{SbCl}_{3}$ in $\left[\mathrm{C}_{4} \mathrm{C}_{1} \mathrm{Im}\right] \mathrm{Cl}$ and $\mathrm{OA}$ yielded phase-pure $\mathrm{Sb}_{2} \mathrm{Se}_{3}$, which was isolated as black precipitate and purified by repeatedly washing with acetonitrile and hexane $(3 x)$. ${ }^{29} \mathrm{Si}$ NMR spectroscopy studies again proved the formation of $\mathrm{Et}_{3} \mathrm{SiCl}$ and $\mathrm{Si}_{2} \mathrm{Et}_{6}$ as was observed for the analogous reaction with $\mathrm{BiCl}_{3}$.

$$
\mathrm{SbCl}_{3}+\left(\mathrm{Et}_{3} \mathrm{Si}\right)_{2} \mathrm{Se} \underset{-\mathrm{OASiEt}_{3},-\mathrm{Et}_{3} \mathrm{SiCl}}{\stackrel{\mathrm{i}}{\longrightarrow}} \mathrm{Sb}_{2} \mathrm{Se}_{3}
$$

i) $\left[\mathrm{C}_{4} \mathrm{C}_{1} \mathrm{Im}\right] \mathrm{Cl}, \mathrm{OA}, 100^{\circ} \mathrm{C}$

Scheme 2. Synthesis of $\mathrm{Sb}_{2} \mathrm{Se}_{3}$ nanoparticles.

The elemental composition of the material as determined by EDX proved the formation of highly stoichiometric $\mathrm{Sb}_{2} \mathrm{Se}_{3}$ (table 1). PXRD studies clearly proved the formation of crystalline $\mathrm{Sb}_{2} \mathrm{Se}_{3}$ nanoparticles (Fig. 8). The peaks can be indexed on the basis of phase-pure $\mathrm{Sb}_{2} \mathrm{Se}_{3}$ (PDF 901-7374). The determined lattice parameters $(a: 1.163(2) \mathrm{nm}, b: 0.397(6)$ $\mathrm{nm}, c: 1.168(1) \mathrm{nm}$ ) were in a very good agreement with the ICDD database for the pure orthorhombic $\mathrm{Sb}_{2} \mathrm{Se}_{3}$ phase. The $X R D$ pattern shows strong preferred orientation of the needlelike $\mathrm{Sb}_{2} \mathrm{Se}_{3}$ structures. Compared to the standard card, the intensity of the (201), (302) and (402) reflections are strongly enhanced. The $\mathrm{Sb}_{2} \mathrm{Se}_{3}$ nanowires preferentially grow along the [010] direction as can be seen from the high intensity of the (hOl) reflections. This conclusion is supported by TEM and SAED and often observed for $\mathrm{Sb}_{2} \mathrm{Se}_{3}$ nanostructures.

Table 1. EDX results of $\mathrm{Bi}_{2} \mathrm{Se}_{3}$ and $\mathrm{Sb}_{2} \mathrm{Se}_{3}$.

\begin{tabular}{llll}
\hline & Bismuth / At.\% & Antimony / At.\% & Selenium / At.\% \\
\hline $\mathrm{Bi}_{2} \mathrm{Se}_{3}$ & $40.5 \pm 0.6$ & - & $59.5 \pm 1.5$ \\
$\mathrm{Sb}_{2} \mathrm{Se}_{3}$ & - & $42.5 \pm 1.5$ & $57.5 \pm 1.0$ \\
\hline
\end{tabular}

$$
2 \Theta /^{\circ}
$$

Figure $8 \mathrm{PXRD}$ of $\mathrm{Sb}_{2} \mathrm{Se}_{3}$ nanoparticles synthesized by reaction of $\left(\mathrm{Et}_{3} \mathrm{Si}\right)_{2} \mathrm{Se}$ with $\mathrm{SbCl}_{3}$ in $\left[\mathrm{C}_{4} \mathrm{C}_{1} \mathrm{Im}\right] \mathrm{Cl}$ in the presence of $\mathrm{OA}$ at $150{ }^{\circ} \mathrm{C}$ and reference for $\mathrm{Sb}_{2} \mathrm{Se}_{3}$ (PDF 900-7374). ${ }^{[35]}$

IR spectroscopy (Fig. 9) and XPS studies (Fig. 10) revealed the existence of an organic capping layer. The carbon concentration is more pronounced than that observed for the $\mathrm{Bi}_{2} \mathrm{Se}_{3}$ particles. The binding energy of the main lines in the $\mathrm{Sb}$ and $\mathrm{Se}$ signals agree well with literature data of $\mathrm{Sb}_{2} \mathrm{Se}_{3}$ surfaces. ${ }^{[36]}$ However, roughly $40 \%$ of the Sb surface atoms of an as-prepared sample are present as antimony oxide or oxoselenide $\left(\mathrm{Sb}_{2} \mathrm{O}_{3}\right.$ or $\mathrm{Sb}_{2}\left(\mathrm{Se}_{\mathrm{x}} \mathrm{O}_{3-\mathrm{x}}\right)_{2}$ but the oxygen content stays constant upon exposure to air. The oxygen signal at $532 \mathrm{eV}$ binding energy increases strongly, showing the oxidation of the capping layer and carbon contaminations on the surface. The Se 3d signal does show a small oxide peak only after one day of exposure to air. No further increase of the Se-oxide content is visible after that. However, the error in the determination of the Se-oxide $\left(\mathrm{Sb}_{2}\left(\mathrm{Se}_{\mathrm{x}} \mathrm{O}_{1-\mathrm{x}}\right)_{3}\right)$ intensity is quite large, due to the weak signal and hence small signal to noise ratio.

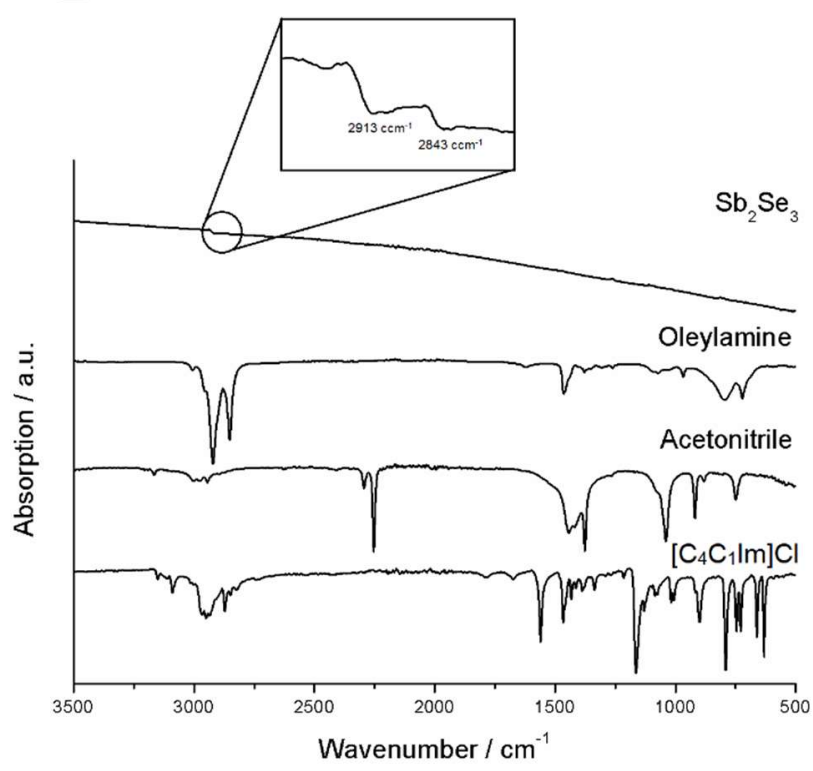

Figure 9. IR spectra of $\mathrm{Sb}_{2} \mathrm{Se}_{3}$ nanoparticles synthesized by reaction of $\left(\mathrm{Et}_{3} \mathrm{Si}\right)_{2} \mathrm{Se}$ with $\mathrm{SbCl}_{3}$ in $\left[\mathrm{C}_{4} \mathrm{C}_{1} \mathrm{Im}\right] \mathrm{Cl}$ in the presence of $\mathrm{OA}$ at $150{ }^{\circ} \mathrm{C}$. 

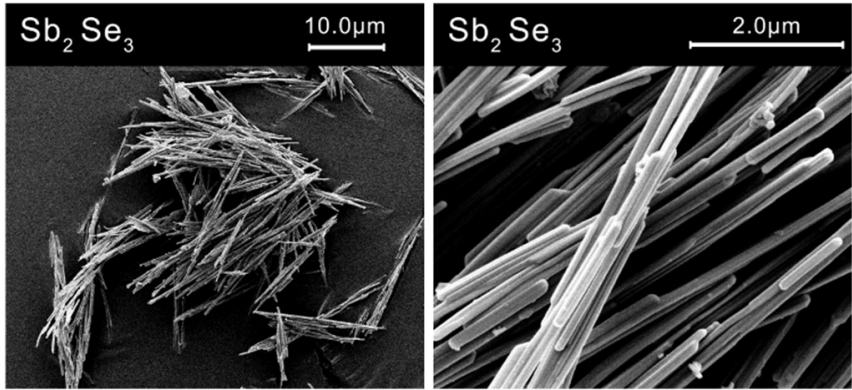

Figure 10. XPS Sb 3d and Se 3d signal of $\mathrm{Sb}_{2} \mathrm{Se}_{3}$ nanoparticles synthesized by reaction of $\left(\mathrm{Et}_{3} \mathrm{Si}\right)_{2} \mathrm{Se}$ with $\mathrm{SbCl}_{3}$ in $\left[\mathrm{C}_{4} \mathrm{C}_{1} \mathrm{Im}\right] \mathrm{Cl}$ in the presence of OA. The intensities of the signals do not change strongly upon exposure to air.

The morphology of the nanoparticles was investigated by SEM and TEM (Fig. 11).
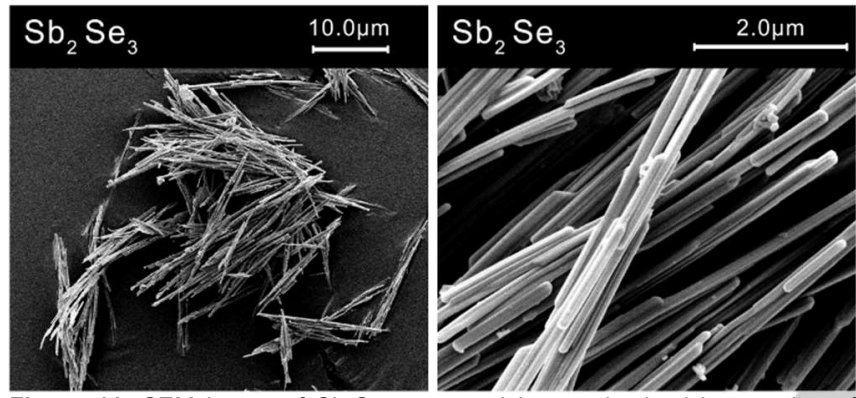

Figure 11. SEM image of $\mathrm{Sb}_{2} \mathrm{Se}_{3}$ nanoparticles synthesized by reaction of $\left(\mathrm{Et}_{3} \mathrm{Si}\right)_{2} \mathrm{Se}$ with $\mathrm{SbCl}_{3}$ in $\left[\mathrm{C}_{4} \mathrm{C}_{1} \mathrm{Im}\right] \mathrm{Cl}$ in the presence of $\mathrm{OA}$ at $150{ }^{\circ} \mathrm{C}$.

SEM photographs proved the formation of agglomerated $\mathrm{Sb}_{2} \mathrm{Se}_{3}$ nanowires with a high aspect ratio. They are up to $5 \mu \mathrm{m}$ in length and show diameters of about $30 \mathrm{~nm}$ (Fig. 11), which is comparable to those previously obtained by polyol processes $(30-50 \mathrm{~nm})^{[37]}$ or by thermal decomposition of the single source precursors $\left(\mathrm{Et}_{2} \mathrm{Sb}\right)_{2} \mathrm{Se}$ and $\mathrm{Et}_{3} \mathrm{SbSe}^{\left[{ }^{19 b}\right]}$

Fig. 12 shows HAADF STEM images of the $\mathrm{Sb}_{2} \mathrm{Se}_{3}$ nanowires. The nanowires have a big aspect ratio with lengths up to $5 \mu \mathrm{m}$ and diameters of about $30 \mathrm{~nm}$. The $\mathrm{Sb}_{2} \mathrm{Se}_{3}$ nanowires are grown along the [010] direction of the stibnite structure in Pnma setting. A high-resolution image of $\mathrm{a} \mathrm{Sb}_{2} \mathrm{Se}_{3}$ nanowire projected along the [001] direction is given in Fig. 12 (right). Due to the contrast in HAADF mode being sensitive to the atomic number $Z$, atomic columns containing only $\mathrm{Se}$ can be distinguished from mixed SbSe columns. The measured distance of the (010) planes is $0.392 \mathrm{~nm}$, which is in good agreement to value of $d_{010}=0.396$ $\mathrm{nm}$ reported in the literature. ${ }^{[38]} \mathrm{A}$ model structure of $\mathrm{Sb}_{2} \mathrm{Se}_{3}$ is overlaid for comparison.

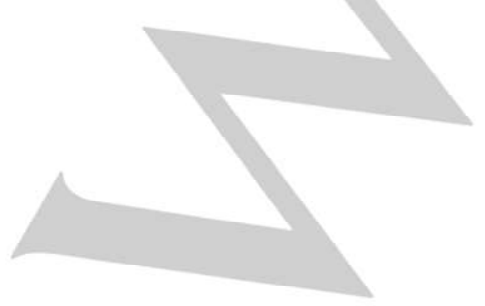

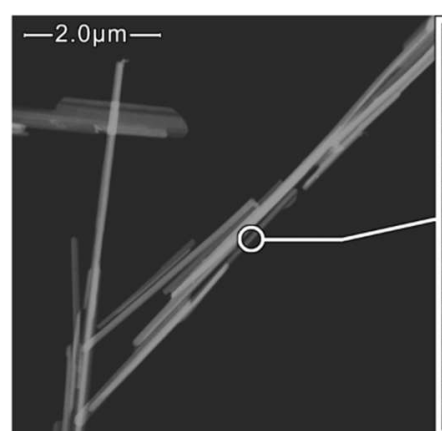

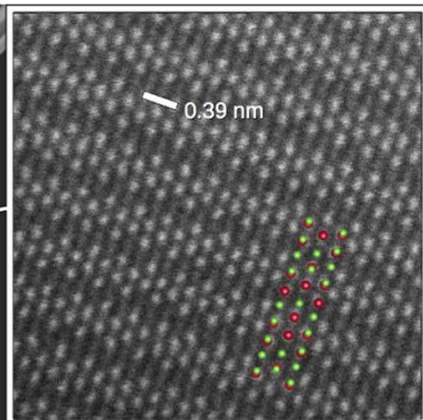

Figure 12. HAADF STEM images of $\mathrm{Sb}_{2} \mathrm{Se}_{3}$ nanoparticles in [001] orientation structure model of $\mathrm{Sb}_{2} \mathrm{Se}_{3}$ as an overlay (red: $\mathrm{Sb}$, green: $\mathrm{Se}$ ).

\section{Conclusions}

Phase-pure crystalline group 15 selenides $\mathrm{M}_{2} \mathrm{Se}_{3}(\mathrm{M}=\mathrm{Sb}, \mathrm{Bi})$ were synthesized under mild reaction conditions by reaction of $\left(\mathrm{Et}_{3} \mathrm{Si}\right)_{2} \mathrm{Se}$ with $\mathrm{SbCl}_{3}$ in $\left[\mathrm{C}_{4} \mathrm{C}_{1} \mathrm{Im}\right] \mathrm{Cl}$ or by reaction with the reactive IL $\left[\mathrm{C}_{4} \mathrm{C}_{1} I \mathrm{~m}\right]_{3}\left[\left.\mathrm{Bi}_{3}\right|_{12}\right]$ containing the trianionic halogenidobismuthate $\left[\left.\mathrm{Bi}_{3}\right|_{12}\right]^{3-}$. Both reactions were performed in the presence of oleylamine, which was found to effectively suppress the homolytic Se-Si bond cleavage reaction, and are scalable to produce of up to $10 \mathrm{~g}$ of the $\mathrm{Sb}_{2} \mathrm{Se}_{3}$ and $\mathrm{Bi}_{2} \mathrm{Se}_{3}$ nanoparticles. In contrast, the reaction of $\left(\mathrm{Et}_{3} \mathrm{Si}\right)_{2} \mathrm{Se}$ with $\left[\mathrm{C}_{4} \mathrm{C}_{1} \mathrm{Im}\right]_{3}\left[\mathrm{BiCl}_{6}\right] \mathbf{1}$, whose solid state structure was determined by single crystal $\mathrm{X}$-ray diffraction, in the presence of oleylamine did not yield phase-pure $\mathrm{Bi}_{2} \mathrm{Se}_{3}$. The crystalline $\mathrm{Sb}_{2} \mathrm{Se}_{3}$ and $\mathrm{Bi}_{2} \mathrm{Se}_{3}$ nanoparticles are covered by a thin IL layer according to XPS results. The particles are relatively stable toward oxidation, in contrast to previously reported $\mathrm{Bi}_{2} \mathrm{Te}_{3}$ nanoparticles. ${ }^{[1]} \mathrm{SEM}$ and TEM studies proved the formation of largely agglomerated nanoparticles, which in case of $\mathrm{Sb}_{2} \mathrm{Se}_{3}$ nanowires exhibited a high aspect ratio. The use of the reactive Bi-containing IL $\left[\mathrm{C}_{4} \mathrm{C}_{1} \mathrm{Im}\right]_{3}\left[\mathrm{Bi}_{3} \mathrm{l}_{12}\right]$ has the great advantage that the concentration of $\mathrm{Bi}$, which must be provided for the formation of $\mathrm{Bi}_{2} \mathrm{Se}_{3}$, is relatively low. As a consequence, the formation of Bi-rich material phases or elemental bismuth is avoided.

\section{Experimental Section}

Synthetic procedures including the synthesis of the IL and thermolysis experiments were performed under inert gas conditions ( $\mathrm{Ar}$ atmosphere) in a glovebox or using standard Schlenk techniques. Acetonitrile (99.9+\% extra dry, Acros), 1-chlorobutane (99\%, ABCR), and N-methylimidazole (99+\%, Sigma Aldrich) were commercially available and used as received, while ethyl acetate (J. T. Baker) was distilled prior to use. $\left(\mathrm{Et}_{3} \mathrm{Si}\right)_{2} \mathrm{Se}$ was prepared according to a literature method. ${ }^{[39]}$

Synthesis of 1-butyl-3-methylimidazolium chloride $\left[\mathrm{C}_{4} \mathbf{C}_{1} \mathrm{Im}\right] \mathrm{Cl}$. In a $100 \mathrm{ml}$ round-bottom flask $8.1 \mathrm{ml}(10 \mathrm{mmol})$ 1-methylimidazole and $13.5 \mathrm{ml}(13 \mathrm{mmol})$ 1-butylchloride were dissolved in $50 \mathrm{ml}$ of acetonitrile. The resulting solution was stirred at $60{ }^{\circ} \mathrm{C}$ for five days. Afterwards the solvent was removed in vacuum until a viscous, yellow oil was received. The oil was added dropwise to $200 \mathrm{ml}$ ice-cooled and stirred ethyl acetate. The resulting white powder was separated by filtration, washed with further cool ethyl acetate and finally dried in vacuum. 
Yield: $16.77 \mathrm{~g}(96.5 \%) .{ }^{1} \mathrm{H}$ NMR $\left(300 \mathrm{MHz}, 25{ }^{\circ} \mathrm{C}, \mathrm{DMSO}-\mathrm{d}_{6}\right): \delta=9.20$ $(\mathrm{s}, 1 \mathrm{H}), 7.76\left(\mathrm{dt},{ }^{3} \mathrm{~J}_{\mathrm{H}-\mathrm{H}}=12.64 \mathrm{~Hz},{ }^{2} \mathrm{~J}_{\mathrm{H}-\mathrm{H}}=1.65 \mathrm{~Hz}, 2 \mathrm{H}\right), 4.17\left(\mathrm{t},{ }^{3} \mathrm{~J}_{\mathrm{H}-\mathrm{H}}=\right.$ $7.2 \mathrm{~Hz}, 2 \mathrm{H}), 3.86(\mathrm{~s}, 3 \mathrm{H}), 1.77\left(\mathrm{dt},{ }^{3} \mathrm{~J}_{\mathrm{H}-\mathrm{H}}=14.9 \mathrm{~Hz},{ }^{3} \mathrm{~J}_{\mathrm{H}-\mathrm{H}}=7.4 \mathrm{~Hz}, 2 \mathrm{H}\right)$, $1.24\left(\mathrm{dq},{ }^{3} \mathrm{~J}_{\mathrm{H}-\mathrm{H}}=14.3 \mathrm{~Hz},{ }^{3} \mathrm{~J}_{\mathrm{H}-\mathrm{H}}=7.2 \mathrm{~Hz}, 2 \mathrm{H}\right), 0.90\left(\mathrm{t},{ }^{3} \mathrm{~J}_{\mathrm{H}-\mathrm{H}}=7.3 \mathrm{~Hz}, 3 \mathrm{H}\right)$.

Synthesis of 1-butyl-3-methylimidazolium iodide $\left[\mathrm{C}_{4} \mathbf{C}_{1} \mathrm{Im}\right] \mathbf{I} .22 \mathrm{~mL}$ (0.276 mol) 1-methylimidazole was dissolved in $100 \mathrm{~mL}$ of acetonitrile and 1-butyliodide $(0.308 \mathrm{~mol}, 35 \mathrm{~mL})$ was added dropwise in the dark at $0{ }^{\circ} \mathrm{C}$. The solution was stirred at ambient temperature for $12 \mathrm{~h}$ and then all volatiles were removed under dynamic vacuum. The resulting residue was washed with $150 \mathrm{~mL}$ of ethyl acetate. After removal of the solvent, the remaining yellowish oil was dried for $72 \mathrm{~h}$ under dynamic vacuum at $50{ }^{\circ} \mathrm{C}$

Yield: $59.47 \mathrm{~g}(81 \%) .{ }^{1} \mathrm{H}$ NMR $\left(300 \mathrm{MHz}, 25^{\circ} \mathrm{C}\right.$, DMSO-d 6 ): $\delta=9.14$ (s, $1 \mathrm{H}), 7.76\left(\mathrm{dt},{ }^{1} \mathrm{~J}_{\mathrm{H}-\mathrm{H}}=13.5 \mathrm{~Hz},{ }^{2} \mathrm{~J}_{\mathrm{H}-\mathrm{H}}=1.7 \mathrm{~Hz}, 2 \mathrm{H}\right), 4.19(\mathrm{t}, 3 \mathrm{JH}-\mathrm{H}=7.2 \mathrm{~Hz}$ $2 \mathrm{H}), 3.88(\mathrm{~s}, 3 \mathrm{H}), 1.79\left(\mathrm{dt},{ }^{1} \mathrm{~J}_{\mathrm{H}-\mathrm{H}}=14.8 \mathrm{~Hz},{ }^{2} \mathrm{~J}_{\mathrm{H}-\mathrm{H}}=7.5 \mathrm{~Hz}, 2 \mathrm{H}\right), 1.29(\mathrm{~m}$ $2 \mathrm{H}), 0.93\left(\mathrm{t},{ }^{3} \mathrm{~J}_{\mathrm{H}-\mathrm{H}}=7.3 \mathrm{~Hz}, 3 \mathrm{H}\right)$

Synthesis of $\left[\mathrm{C}_{4} \mathrm{C}_{1} / \mathrm{m}\right]_{3}\left[\mathrm{Bi}_{3} \mathrm{I}_{12}\right] .14 .91 \mathrm{~g}(0.561 \mathrm{~mol})\left[\mathrm{C}_{4} \mathrm{C}_{1} \mathrm{Im}\right] \mathrm{l}$ and 27.57 $\mathrm{g}(0.468 \mathrm{~mol}) \mathrm{Bil}_{3}$ were added to $500 \mathrm{~mL}$ ethanol and the resulting suspension was stirred at ambient temperature for $5 \mathrm{~d}$. The resulting bright yellow solid was separated via filtration, washed with $100 \mathrm{ml}$ of ethanol and carefully dried for $72 \mathrm{~h}$ under dynamic vacuum at ambient temperature.

Yield: $30.87 \mathrm{~g}(77.16 \%)$. Melting point: $98^{\circ} \mathrm{C}$. Elemental analysis (EDX): Bi: $19.8 \pm 1$ at\%, I: $80.2 \pm 1.7$ at\%. ${ }^{1} \mathrm{H}$ NMR (300 MHz, $\left.25{ }^{\circ} \mathrm{C}, \mathrm{DMSO}-\mathrm{d}_{6}\right)$ : $\delta=9.11(\mathrm{~s}, 1 \mathrm{H}), 7.73\left(\mathrm{dt},{ }^{1} \mathrm{~J}_{\mathrm{H}-\mathrm{H}}=20.2 \mathrm{~Hz},{ }^{2} \mathrm{~J}_{\mathrm{H}-\mathrm{H}}=1.8 \mathrm{~Hz}, 2 \mathrm{H}\right), 4.16\left(\mathrm{t},{ }^{3} \mathrm{~J}_{\mathrm{H}-}\right.$ $\mathrm{H}=7.2 \mathrm{~Hz}, 2 \mathrm{H}), 3.85(\mathrm{~s}, 3 \mathrm{H}), 1.76(\mathrm{~m}, 2 \mathrm{H}), 1.29(\mathrm{~m}, 2 \mathrm{H}), 0.93\left(\mathrm{t},{ }^{3} \mathrm{~J}_{\mathrm{H}-\mathrm{H}}=\right.$ $7.3 \mathrm{~Hz}, 3 \mathrm{H})$.

Synthesis of $\left[\mathrm{C}_{4} \mathrm{C}_{1} \mathrm{Im}\right]_{3}\left[\mathrm{BiCl}_{6}\right] .1 .25 \mathrm{~g}(7.18 \mathrm{mmol})$ of $\left[\mathrm{C}_{4} \mathrm{C}_{1} \mathrm{Im}\right] \mathrm{Cl}$ and $0.75 \mathrm{~g}(2.37 \mathrm{mmol})$ of $\mathrm{BiCl}_{3}$ were stirred at $120{ }^{\circ} \mathrm{C}$ for $4 \mathrm{~h}$. The resulting highly viscous, white liquid was used without further purification.

Yield: $2.0 \mathrm{~g}(100 \%)$. Elemental analysis (EDX): $\mathrm{Bi}: 13.8 \pm 0.5$ at\%, $\mathrm{Cl}$ : $86.2 \pm 2$ at\%. ${ }^{1} \mathrm{H}$ NMR (300 MHz, $25{ }^{\circ} \mathrm{C}$, DMSO-d $): \delta=9.41(\mathrm{~s}, 1 \mathrm{H})$, $7.79\left(\mathrm{dt},{ }^{1} \mathrm{~J}_{\mathrm{HH}}=20.3,{ }^{2} \mathrm{~J}_{\mathrm{H}-\mathrm{H}}=1.7 \mathrm{~Hz}, 2 \mathrm{H}\right), 4.21\left(\mathrm{t},{ }^{3} \mathrm{~J}_{\mathrm{H}-\mathrm{H}}=7.2 \mathrm{~Hz}, 2 \mathrm{H}\right)$, $3.89(\mathrm{~s}, 3 \mathrm{H}), 1.75(\mathrm{~m}, 2 \mathrm{H}), 1.23(\mathrm{~m}, 2 \mathrm{H}), 0.86\left(\mathrm{t},{ }^{3} \mathrm{~J}_{\mathrm{H}-\mathrm{H}}=7.3 \mathrm{~Hz}, 3 \mathrm{H}\right)$.

Synthesis of $\left[\mathrm{C}_{4} \mathbf{C}_{1} \mathrm{Im}\right]_{3}\left[\mathrm{SbCl}_{6}\right] .1 .40 \mathrm{~g}(8.04 \mathrm{mmol})$ of $\left[\mathrm{C}_{4} \mathrm{C}_{1} \mathrm{Im}\right] \mathrm{Cl}$ and $0.60 \mathrm{~g}(2.66 \mathrm{mmol})$ of $\mathrm{SbCl}_{3}$ were stirred at $120{ }^{\circ} \mathrm{C}$ for $4 \mathrm{~h}$. The resulting highly viscous, clear liquid was used without further purification.

Yield: $2 \mathrm{~g}(100 \%)$. Elemental analysis (EDX): Sb: $14.9 \pm 1.2 \mathrm{at} \%, \mathrm{Cl}$ : $85.1 \pm 1.6$ at\%. ${ }^{1} \mathrm{H}$ NMR (300 MHz, $\left.25{ }^{\circ} \mathrm{C}, \mathrm{DMSO}-\mathrm{d}_{6}\right): \delta=9.38(\mathrm{~s}, 1 \mathrm{H})$, $7.80(\mathrm{~m}, 2 \mathrm{H}), 4.18\left(\mathrm{t},{ }^{3} \mathrm{~J}_{\mathrm{H}-\mathrm{H}}=7.2 \mathrm{~Hz}, 2 \mathrm{H}\right), 3.86(\mathrm{~s}, 3 \mathrm{H}), 1.75(\mathrm{~m}, 2 \mathrm{H}), 1.23$ $(\mathrm{m}, 2 \mathrm{H}), 0.87\left(\mathrm{t},{ }^{3} \mathrm{~J}_{\mathrm{H}-\mathrm{H}}=7.3 \mathrm{~Hz}, 3 \mathrm{H}\right)$.

Synthesis of $\mathrm{Sb}_{2} \mathrm{Se}_{3}$ nanoparticles. In a centrifuge tube $400 \mathrm{mg}(1.8$ mmol) $\mathrm{SbCl}_{3}, 1 \mathrm{ml}$ olelyamine and $4 \mathrm{~g}\left[\mathrm{C}_{4} \mathrm{C}_{1} \mathrm{~lm}\right] \mathrm{Cl}$ were stirred at $100{ }^{\circ} \mathrm{C}$ for 30 minutes. To the resulting solution $200 \mu \mathrm{l}(0.7 \mathrm{mmol})\left(\mathrm{Et}_{3} \mathrm{Si}\right)_{2} \mathrm{Se}$ were added and thoroughly stirred. The black suspension was stirred at $150{ }^{\circ} \mathrm{C}$ for $12 \mathrm{~h}$. The formed colloidal solution was centrifuged ( $2500 \mathrm{rpm}$ ) and washed with $6 \times 15 \mathrm{~mL}$ acetonitrile. The separated particles were dried in vacuum at ambient temperature.

Synthesis of $\mathrm{Bi}_{2} \mathrm{Se}_{3}$ nanoparticles. In a centrifuge tube $1400 \mathrm{mg}(1.6$ $\mathrm{mmol})\left[\mathrm{C}_{4} \mathrm{C}_{1} \mathrm{Im}\right]_{3}\left[\mathrm{Bi}_{3} \mathrm{l}_{12}\right], 1 \mathrm{ml}$ olelyamine and $4 \mathrm{~g}\left[\mathrm{C}_{4} \mathrm{C}_{1} \mathrm{~lm}\right] \mathrm{l}$ were stirred at $100{ }^{\circ} \mathrm{C}$ for 30 minutes. To the resulting red solution $200 \mu \mathrm{l}(0.7 \mathrm{mmol})$ $\left(\mathrm{Et}_{3} \mathrm{Si}\right)_{2} \mathrm{Se}$ were added and thoroughly stirred. The black suspension was stirred at $150{ }^{\circ} \mathrm{C}$ for $12 \mathrm{~h}$. The formed colloidal solution was centrifuged
(2500 rpm) and washed with $6 \times 15 \mathrm{~mL}$ acetonitrile. The separated particles were dried in vacuum at ambient temperature.

NMR spectroscopy. ${ }^{1} \mathrm{H}(300 \mathrm{MHz})$ and ${ }^{13} \mathrm{C}\left\{{ }^{1} \mathrm{H}\right\}(75.5 \mathrm{MHz}) \mathrm{NMR}$ spectra $(\delta$ in ppm) were recorded using a Bruker Avance DPX-300 spectrometer and were referenced to internal DMSO-d $\mathrm{d}_{6}\left({ }^{1} \mathrm{H}: \delta=2.50\right.$; $\left.{ }^{13} \mathrm{C}: \delta=39.51\right)$ or $\mathrm{CDCl}_{3}\left({ }^{1} \mathrm{H}: \delta=7.26 ;{ }^{13} \mathrm{C}: \delta=77.16\right)$.

IR spectroscopy. IR spectra were recorded in a glovebox using an ALPHA-T FT-IR spectrometer equipped with a single reflection ATR sampling module.

Single crystal X-ray diffraction. Crystallographic data data of 1 were collected on a Bruker D8 Kappa APEX2 diffractometer (MoK ${ }_{\alpha}$ radiation, $\lambda$ $=0.71073 \AA$ ) at $100(2) \mathrm{K}\left[\mathrm{C}_{24} \mathrm{H}_{45} \mathrm{BiCl}_{6} \mathrm{~N}_{6}\right], M=839.34$, colourless crystal, $(0.199 \times 0.173 \times 0.116 \mathrm{~mm})$; orthorhombic, space group Pna21; $a=$ 32.5929(14) $\AA, b=12.6604(5) \AA, c=16.6457(7) \AA ; \alpha=90^{\circ}, \beta=90^{\circ}, \gamma=$ $90^{\circ}, V=6868.7(5) \AA^{3} ; Z=8 ; \mu=5.624 \mathrm{~mm}^{-1} ; \rho_{\text {calc }}=1.623 \mathrm{~g} \cdot \mathrm{cm}^{-3}$ 196857 reflections $\left(\theta_{\max }=33.252^{\circ}\right), 24997$ unique $\left(R_{\text {int }}=0.0384\right) ; 695$ parameters; Flack-Parameter $x=0.458(3)$; largest max. $/$ min in the final difference Fourier synthesis $1.300 \mathrm{e} \cdot \AA^{-3} /-0.986 \mathrm{e} \cdot \AA^{-3}$; max./min transmission $0.48 / 0.27 ; R_{1}=0.0283(\mathrm{I}>2 \sigma(\mathrm{I})), w R_{2}=0.0526$ (all data). The solid-state structure of $\mathbf{1}$ is shown in Figure 7 . The structure was solved by Direct Methods (SHELXS-97) ${ }^{[40]}$ and refined anisotropically by full-matrix least-squares on $\mathrm{F}^{2}$ (SHELXL-2014). ${ }^{[41]}$ Absorption corrections were performed numerical based on indexed faces (Bruker AXS APEX2). Hydrogen atoms were refined using a riding model or rigid methyl groups. The crystal was twinned by inversion and the model refined accordingly. One of the butyl groups is disordered over two positions. The minor compound could only be refined with a single mutual isotropic displacement parameter. The ADP of the major component suggest further disorder that could not be resolved.

The crystallographic data of $\mathbf{1}$ (excluding structure factors) have been deposited with the Cambridge Crystallographic Data Centre as supplementary publication no. CCDC-1502363. Copies of the data can be obtained free of charge on application to CCDC, 12 Union Road, Cambridge, CB21EZ (fax: (+44) 1223/336033; e-mail: deposit@ccdc.cam-ak.uk).

X-ray Analysis. PXRD patterns were obtained using a Bruker D8 Advance powder diffractometer with $\mathrm{Cu}$ Ka radiation $(\lambda: 1.5418 \AA, 40 \mathrm{kV}$ and $40 \mathrm{~mA}$ ) using a silicon single crystal as sample holder to minimize scattering. The powders were re-dispersed in ethanol on the silicon surface and then investigated in the range from 10 to $90^{\circ} 2 \theta$ with a step size of $0.01^{\circ} 2 \theta$ with a counting time of $0.6 \mathrm{~s}$. Rietveld refinement was performed with the program package TOPAS 5.0 (Bruker) to determine the lattice parameters and average crystallite size by use of the Scherrer equation with the program package TOPAS 5.0 (Bruker). ${ }^{[42]}$ The background was modelled using Chebyshev polynomials. The structure models of $\mathrm{Sb}_{2} \mathrm{Se}_{3}\left(\# 85676\right.$ ) and $\mathrm{Bi}_{2} \mathrm{Se}_{3}(\# 72545)$ from the ICSD database were used. For each Rietveld refinement, the instrumental correction as determined with a standard powder sample from NIST (National Institute of Standards and Technology) as standard reference material (SRM $660 \mathrm{~b} ; \mathrm{a}(\mathrm{LaB} 6)=4.15689 \AA$ ) was taken into account.

XPS. XPS studies were performed using a Versaprobe II $^{\mathrm{TM}}$ (Ulvac-Phi) with monochromatic $\mathrm{Al} \mathrm{K} \alpha$ light at $1486.6 \mathrm{eV}$ photon energy. The emission angle between analyzer and sample is $45^{\circ}$. The $\mathrm{Cu} 2 \mathrm{p}$ signal at $932.67 \mathrm{eV}$ binding energy of a sputter-cleaned $\mathrm{Cu}$ foil was used as the binding energy reference. The foil and the powder were put onto insulating double-sided tape and charging effects were compensated 
using a dual-beam neutralizing approach using electrons and slow moving argon ions.

Electron microscopy. Particle size and morphology as well as elemental composition of the powders were analyzed by scanning electron microscopy (SEM) using a Jeol JSM 6510 microscope equipped with a Bruker Quantax 400 spectrometer (EDX, chemical composition). High-resolution STEM studies were carried out on a Jeol JEM 2200fs microscope equipped with probe-side Cs-corrector operated at $200 \mathrm{kV}$ acceleration voltage.

\section{Acknowledgements}

S. Schulz acknowledges financial support by the Deutsche Forschungsgemeinschaft (DFG) within the Priority Program SPP 1708 "Material Synthesis near Room Temperature" and the University of Duisburg-Essen.

Keywords: Bismuth • Antimony • Selenium • Thermoelectric Material • Ionic Liquid

[1] a) D. Y. W. Yu, H. E. Hoster, Sci. Rep. 2014, 4, 4562/1-4562/6; b) D. Y.W. Yu, P. V. Prikhodchenko, Nat. Commun. 2013, 4, 2922-2928; c) P V. Prikhodchenko, J. Gun, Chem. Mater. 2012, 24, 4750-4757.

[2] a) Y. C. Choi, T. N. Mandal, W. S. Yang, Y. H. Lee, S. H. Im, J. H. Noh and S. I. Seok, Angew. Chem. 2014, 126, 1353-1357; Angew. Chem. Int. Ed. 2014, 53, 1329-1333; b) F. T. F. O'Mahony, U. B. Cappel, N. Tokmoldin, T. Lutz, R. Lindblad, H. Rensmo, S. A. Haque, Angew. Chem. 2013, 125, 12269 -12273; Angew. Chem. Int. Ed. 2013, 52 12047-12051; c) J. A. Chang, J. H. Rhee, S. H. Im, Y. H. Lee, H.-J. Kim S. I. Seok, M. K. Nazeeruddin and M. Grätzel, Nano Lett. 2010, 10, 2609-2612; d) B. Zhou, J. Zhu, Nanotechnology 2009, 20, 085604.

[3] a) W. Liu, Z. Zhang, X. Peng, J. Zhong, Phys. B: Cond. Matter 2015, 456, 355-358; b) D. Koumoulis, B. Leung, T. C. Chasapis, R. Taylor, D. Jr. King, M. G. Kanatzidis, L.-S. Bouchard, Adv. Funct. Mater. 2014, 24 1519-1528; c) J.-J. Zhou, W. Feng, Y. Zhang, S. A. Yang, Y. Yao, Sci. Rep. 2014, 4, 3841/1-3841/6; d) Z. Xu, X. Guo, M. Yao, H. He, L. Miao, L. Jiao, H. Lin, J. Wang, D. Qian, J. Jia, W. Ho, M. Xie, Adv. Mater 2013, 25, 1557-1562; e) Z. Wang, R. L. J. Qiu, C. H. Lee, Z. Zhang, X. P. A. Gao, ACS Nano 2013, 7, 2126-2131; f) J. Zhang, C.-Z. Chang, Z. Zhang, J. Wen, X. Feng, K. Li, M. Liu, K. He, L. Wang, X. Chen, Q.-K. Xue, X. Ma, Y. Wang, Nat. Comm. 2011, 2, 1588/1-1588/6; g) M. Z. Hasan, C. L. Kane, Rev. Mod. Phys. 2010, 82, 3045-3067; h) M. König S. Wiedmann, C. Brüne, A. Roth, H. Buhmann, L. W. Molenkamp, X.-L. Qi, S.-C. Zhang, Science 2007, 318, 766-770; i) F. E. Camino, W. Zhou, V. J. Goldman, Phys. Rev. Lett. 2005, 95, 246802/1-4.

[4] a) H. S. Shin, B. Hamdou, H. Reith, H. Osterhage, J. Gooth, C. Damm, B. Rellinghaus, E. Pippel, K. Nielsch, Nanoscale 2016, 8, 1355213557 ; b) G. L. Sun, L. L. Li, X. Y. Qin, D. Li, T. H. Zou, H. X. Xin, B. J. Ren, J. Zhang, Y. Y. Li, X. J. Li, Appl. Phys. Lett. 2015, 106, 053102; c) Z. Lu, L. P. Tan, X. Zhao, M. Layani, T. Sun, S. Fan, Q. Yan, S. Magdassi, H. H. Hng, J. Mater. Chem. C 2013, 1, 6271-6277; d) A. J. Minnich, M. S. Dresselhaus, Z. F. Ren, G. Chen, Energy Environ. Sci. 2009, 2, 466-479.

[5] a) Y. Zhang, G. D. Stucky, Chem. Mater. 2014, 26, 837-848; b) R. Benoit, V. Hornebecq, F. Weill, L. Lecren, X. Bourrat, M. TregnerDelapierre, Mater. Chem. A 2013, 1, 14221-14226; c) M.-R. Gao, Y.-F Xu, J. Jiang, S.-H. Yu, Chem. Soc. Rev. 2013, 42, 2986-3017; d) R. J. Mehta, C. Karthik, B. Singh, R. Teki, T. Borca-Tasciuc, G. Ramanath, ACS Nano 2010, 4, 5055-5060; e) G. Zhang, Q. Yu, X. Li, Dalton Trans. 2010, 39, 993-1004.
[6] B. Pejova, I. Grodzanov, A. Tanuševski, Mater. Chem. Phys. 2004, 83 245-249.

[7] R. Vadapoo, S. Krishnan, H. Yilmaz, C. Marin, Phys. Status Solidi B 2011, 248, 700-705

[8] a) N. W. Tideswell, F. H. Kruse, J. D. McCullough, Acta Crystallogr. 1957, 10, 99-102; b) G. P. Voutsas, A. G. Papazoglou, P. J Rentzeperis, D. Siapkas, Z. Kristallogr. 2010, 171, 261-268; c) V. L. Deringer, R. P. Stoffel, M. Wuttig, R. Dronskowski, Chem. Sci. 2015, 6 5255-5262

[9] R. W. G. Wyckoff, Crystal Structures, 2nd Edition, Krieger, Malabar 1986.

[10] a) Zheng, X. W.; Xie, Y.; Zhu, L. Y.; Jiang, X. C.; Jia, Y. B.; Song, W. H.; Sun, Y. P. Inorg. Chem. 2002, 41, 455-461; b) Gribnyak, L. G.; Ivanova, T. B. Inorg. Mater. 1987, 23, 478-482; c) B. R. Chakraborty, B Ray, R. Bhattacharya, A. K. Dutta, J. Phys. Chem. Solids 1980, 41 913-917.

[11] D. Choi, Y. Jang, J. Lee, G. H. Jeong, D. Whang, S. W. Hwang, K.-S. Cho, S.-W. Kim, Sci. Rep. 2014, 4, 6714/1-7.

[12] a) Y. Liang, Y. Wang, J. Wang, S.i Wu, D. Jiang, J. Lian, RSC Adv. 2016, 6, 11501-11506; b) R. Jin, G. Chen, C. Yan, D. Chen, H. Xu, J. Pei, Cryst. Eng. Comm. 2012, 14, 8547-8553; c) L. Guo, G. B. Ji, X. F. Chang, M. B. Zheng, Y. Shi, Y. D. Zheng, Nanotechnology 2010, 21, 035606; d) Y. Chen, B. Deng, G. B. Cai, T. K. Zhang, W. F. Dong, W. X. Zhang, A. W. Xu, J. Phys. Chem. C 2008, 112, 672-679.

[13] Y.-Q. Liu, M. Zhang, F.-X. Wang, G.-B. Pan, J. Mater. Chem. C 2014, 2, 240-244.

[14] R. J. Mehta, C. Karthik, W. Jiang, B. Singh, Y. Shi, R. W. Siegel, T. Borca-Tasciuc, G. Ramanath, Nano Lett. 2010, 10, 4417-4422.

[15] G. Chen, W. Wang, C. Wang, T. Ding, Q. Yang, Adv. Sci. 2015, 2 1500109

[16] a) J. Buha, R. Gaspari, A. E. Del Rio Castillo, F. Bonaccorso, L. Manna Nano Lett. 2016, 16, 4217-4223; b) M. Hong, Z.-G. Chen, L. Yang, G Han, J. Zou, Adv. Electron. Mater. 2015, 1, 1500025/1-9; c) A. Zhuang J.-J. Li, Y.-C. Wang, X. Wen, Y. Lin, B. Xiang, X. Wang, J. Zeng, Angew. Chem. 2014, 126, 6543-6547; Angew. Chem. Int. Ed. 2014, 53 6425-6429; d) Z. Lin, Y. Chen, A. Yin, Q. He, X Huang, Y. Xu, Y. Liu, X. Zhong, Y. Huang, X. Duan, Nano Letters 2014, 14,6547-6553; e) H. Xu, G. Chen, R. Jin, D. Chen, Y. Wang, J. Pei, Y. Zhang, C. Yan, Z. Qiu, Cryst. Eng. Comm. 2014, 16, 3965-3970; f) Y. Min, G. D. Moon, B. S Kim, B. Lim, J.-S. Kim, C. Y. Kang,U. Jeong, J. Am. Chem. Soc. 2012 134, 2872-2875

[17] a) G. Bendt, J. Sonntag, A. Lorke, W. Assenmacher, U. Hagemann, S. Schulz, Semicond. Sci. Technol. 2015, 30, 085021/1-7; b) G. Bendt, S Schulz, S. Zastrow, K. Nielsch, Chem. Vap. Deposition 2013, 19, 235241.

[18] a) C. Bae, T. Böhnert, J. Gooth, L. Seulky, S. Lee, H. Kim, S. Heimann S. Schulz, H. Shin, K. Nielsch, Semicond. Sci. Technol. 2014, 29 064003/1-7; b) S. Zastrow, J. Gooth, T. Böhnert, S. Heiderich, W Töllner, S. Heimann, S. Schulz, K. Nielsch, Semicond. Sci. Technol. 2013, 28, 035010/1-6.

[19] a) M. Rusek, G. Bendt, C. Wölper, S. Schulz, Eur. J. Inorg. Chem. 2016 3673-3679; b) S. Heimann, W. Assenmacher, O. Prymak, S. Schulz Eur. J. Inorg. Chem. 2015, 14, 2407-2415; c) G. Bendt, A. Weber, S Heimann, W. Assenmacher, O. Prymak, S. Schulz, Dalton Trans. 2015 44, 14272-14280; d) S. Schulz, S. Heimann, J. Friedrich, M. Engenhorst, G. Schierning, W. Assenmacher, Chem. Mater. 2012, 24 2228-2234.

[20] S. Heimann, S. Schulz, J. Schaumann, A. Mudring, J. Stölzel, F Maculewicz, G. Schierning, J. Mater. Chem. C 2015, 3, 10375-10380.

[21] M. Loor, G. Bendt, C. Wölper, W. Assenmacher, S. Schulz, Dalton Trans. 2016, DOI: 10.1039/C6DT02361D.

[22] S. Schulz, S. Heimann, K. Kaiser, O. Prymak, W. Assenmacher, J. T. Brüggemann, B. Mallik, A.-V. Mudring, Inorg. Chem. 2013, 52, 1432614333. 
[23] a) A. J. Green, S. Dey, Y. Q. An, B. O'Brien, S. J. O'Mullane, B. Thiel, A. C. Diebold, arXiv:1601.04057v1 [cond-mat.mtrl-sci]; b) C. D. Wagner, A V. Naumkin, A. Kraut-Vass, J. W. Allison, C. J. Powell and J. R. Rumble Jr., NIST Standard Reference Database 20, Version 3.4. (web version) (http:/srdata.nist.gov/xps/).

[24] C. R. Thomas, M. K. Vallon, M. G. Frith, H. Sezen, S. K. Kushwaha, R. J. Cava, J. Schwartz, S. L. Bernasek, Chem. Mater. 2016, 28, 35-39.

[25] a) C. R. Thomas, G. Sahasrabudhe, S. K. Kushwaha, J. Xiong, R. J. Cava, J. Schwartz, Status Solidi RRL 2014, 8, 997-1002; b) L. V. Yashina, J. Sánchez-Barriga, M. R. Scholz, A. a.; Volykhov, A. P. Sirotina, V. S. Neudachina, M. E.; Tamm, A. Varykhalov, ACS Nano 2013, 7, 5181-5191; c) H. Bando, K. Koizumi, Y. Oikawa, K. Daikohara V. A. Kulbachinskii, H.Ozaki, J. Phys. Condens. Matter 2000, 12, 56075616 .

[26] S. Nakajima, J. Phys. Chem. Solids 1963, 24, 479-485

[27] a) K. Kadel, L. Kumari, W. Li, J. Y. Huang, P. P. Provencio, Nanoscale Res. Lett. 2016, 6, 57; b) R. Harpness, A. Gedanken, New J. Chem. 2003, 27, 1191-1193

[28] S. A. Semiletov, Z. G. Pinsker, Dokl. Akad. Nauk SSSR 1955, 100, 1079-1082.

[29] a) K. Kadel, L. Kumari, W. Li, J.Y. Huang, P. P. Provencio, Nanoscale Res. Lett. 2011, 6, 57/1-7; b) G. Zhang, W. Wang, X. Lu, X. Li, Cryst. Growth Design 2009, 9, 143-150; c) R. Y. Wang, J. P. Feser, X. Gu, K. M. Yu, R. A. Segalman, A. Majumdar, D. J. Miliron, J. J. Urban, Chem. Mater. 2010, 22, 1943-1945; d) H. Cui, H. Liu, X. Li, J. Wang, F. Han, X Zhang, R. I. Boughton, J. Sol. State Chem. 2004, 177, 4001-4006.

[30] a) F. Wei, Z. Deng, S. Sun, F. Xie, G. Kieslich, D. M. Evans, M. A. Carpenter, Paul D. Bristowe, A. K. Cheetham, Mater. Horiz. 2016, 3 328-332; b) N. Elfaleh, H. Chouaib, S. Kamoun, Acta Cryst. 2013, E69 m666; c) A. S. Rao, U. Baruah, S. K. Das, Inorg. Chim. Acta 2011, 372, 206-212; d) B. Zarychta, M. Bujak, J. Zaleski, Z. Naturforsch. 2004, 59b, 1029-1034.

[31] Cambridge Structural Database, Version 5.37, see also: F. H. Allen, Acta Cryst., 2002, B58, 380-388. Analysis based on 44 hits including a $\mathrm{BiCl}_{6}$ with co-ordination number of $\mathrm{Cl}$ set to 1 . The opposing bond lengths were isolated by constraining the angle at $\mathrm{Bi}$ to be $<150^{\circ}$.

[32] A. Guy Orpen, M. J. Quayle, Dalton Trans. 2001, 1601-1610.

[33] a) L. E. Orgel, J. Chem. Soc. 1959, 3815-3819; b) R. A. Wheeler, P. N. V. P. Kumar, J. Am. Chem. Soc. 1992, 114, 4776.

[34] a) S. Pohl, R. Lotz, W. Saak, D. Haase, Angew. Chem. 1989, 101, 355 357; Angew. Chem. Int. Ed. 1989, 28, 344-345; b) C. Vitzthumecker, A. Pfitzner, Z. Anorg. Allg. Chem. 2014, 640, 2366.

[35] R. Caracas, X. Gonze, Phys. Chem. Minerals 2005, 32, 295-300.

[36] a) G. Chen, J. Zhou, J. Zuo, Q. Yang, Appl. Mater. Interfaces 2016, 8, 2819-2825; b) C. D. Wagner, A. V. Naumkin, A. Kraut-Vass, J. W Allison, C. J. Powell, J. R. Rumble Jr., NIST Standard Reference Database 20, Version 3.4. (web version) (http:/srdata.nist.gov/xps/).

[37] a) Z. Deng, M. Mansuripur, A. J. Muscat, Nano Lett. 2009, 9, $2015-$ 2020; b) W. Tao, J. Wang, D. Wu, J. Chang, F. Wang, Z. Gao, F. Xu, K Jiang, Dalton Trans. 2013, 42, 11411-11417; c) H. Zhang, M. Ge, L. Yang, Z. Zhou, W. Chen, Q. Li, L. Liu, J. Phys. Chem. C 2013, 117, 10285-10290.

[38] ICSD651518: O. M. Aliev, E. V. Magerramov, P. G. Rustamov, Russ. J. Inorg. Chem. (Z. Neorgan. Khimii) 1977, 22, 1539-1541.

[39] M. R. Detty, M. D. Seidler, J. Org. Chem. 1982, 47, 1354-1356.

[40] G. M. Sheldrick, Acta Crystallogr. 1990, A46, 467-473

[41] a) Sheldrick, G. M. SHELXL-2014, Program for the Refinement of Crystal Structures University of Göttingen, Göttingen (Germany) 2014 see also: G. M. Sheldrick, Acta Crystallogr. 2008, A64, 112-122); b) shelXle, A Qt GUI for SHELXL, C. B. Hübschle, G. M. Sheldrick, B. Dittrich, J. Appl. Cryst. 2011, 44, 1281-1284.

[42] P. Scherrer, Nachr. Ges. Wiss. Gött., Math.-Phys. KI. 1918, 2, 98-100. 


\section{Entry for the Table of Contents}

\section{FULL PAPER}

Crystalline $\mathrm{Sb}_{2} \mathrm{Se}_{3}$ and $\mathrm{Bi}_{2} \mathrm{Se}_{3}$ nanoparticles were prepared by wet chemical processes using ionic liquids as reagent and solvent and characterized by EDX, XPS, IR, SEM and TEM.
M. Loor, G. Bendt, J. Schaumann, U.
$3\left[\mathrm{C}_{4} \mathrm{C}_{1} \mathrm{Im}\right] 1+3 \mathrm{Bil}_{3} \longrightarrow\left[\mathrm{C}_{4} \mathrm{C}_{1} \mid \mathrm{m}\right]_{3}\left[\mathrm{Bi}_{3} \mathrm{l}_{12}\right]$

$\left[\mathrm{C}_{4} \mathrm{C}_{1} \mid \mathrm{m}\right]_{3}\left[\mathrm{Bi}_{3} \mathrm{I}_{12}\right]+\left(\mathrm{Et}_{3} \mathrm{Si}\right)_{2} \mathrm{Se} \stackrel{\left[\mathrm{C}_{4} \mathrm{C}_{1} \mathrm{Im}\right] \mathrm{l}}{\longrightarrow} \mathrm{Bi}_{2} \mathrm{Se}_{3}$ $\mathrm{SbCl}_{3}+\left(\mathrm{Et}_{3} \mathrm{Si}\right)_{2} \mathrm{Se} \stackrel{\left[\mathrm{C}_{4} \mathrm{C}_{1} \mathrm{Im}\right] \mathrm{Cl}}{\longrightarrow} \mathrm{Sb}_{2} \mathrm{Se}_{3}$ $\mathrm{Bi}_{2} \mathrm{Se}_{3}$

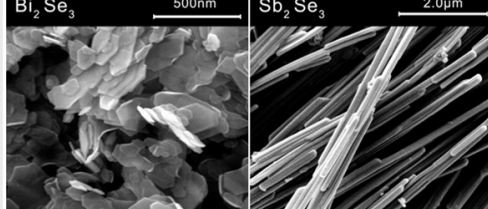
Hagemann, M. Heidelmann, C. Wölper, S. Schulz*

Page No. - Page No.

Synthesis of $\mathrm{Sb}_{2} \mathrm{Se}_{3}$ and $\mathrm{Bi}_{2} \mathrm{Se}_{3}$ Nanoparticles in lonic Liquids at Low Temperatures and Solid State Structure of $\left[\mathrm{C}_{4} \mathrm{C}_{1} / \mathrm{m}\right]_{3}\left[\mathrm{BiCl}_{6}\right]$ 
Additional Author information for the electronic version of the article.

Stephan Schulz: $\quad$ orcid.org/0000-0003-2896-4488 
DuEPublico

Duisburg-Essen Publications online
DESISEN R G

offen im Denken

Ub $\begin{aligned} & \text { universitäts } \\ & \text { bibliothek }\end{aligned}$

This text is made available via DuEPublico, the institutional repository of the University of Duisburg-Essen. This version may eventually differ from another version distributed by a commercial publisher.

DOI: $\quad 10.1002 /$ zaac.201600325

URN: urn:nbn:de:hbz:464-20201208-094758-7

This is the peer reviewed version of the following article: Z. Anorg. Allg . Chem. 2017, 643,1, Special Issue: Reactions in Ionic Liquids, 60-68, which has been published in final form at: https://doi.org/10.1002/zaac.201600325

All rights reserved. 